\title{
Mercedes of Castile, or, The Voyage to Cathay by James Fenimore Cooper A Critical Edition of the Preface and Chapter 23
}

\author{
Stephanie Anne Kingsley \\ Atlanta, Georgia \\ Bachelor of Arts, English and Spanish \\ University of Georgia, 2010
}

\begin{abstract}
A Thesis presented to the Graduate School of Arts and Sciences of the University of Virginia in Candidacy for the Degree of Master of Arts
\end{abstract}

Department of English

University of Virginia

May 2014 
Table of Contents

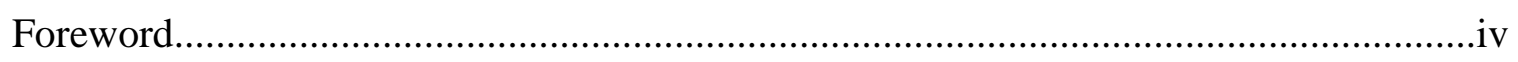

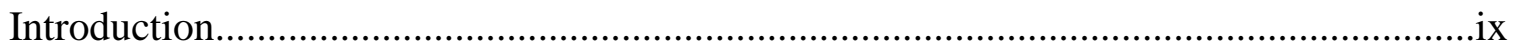

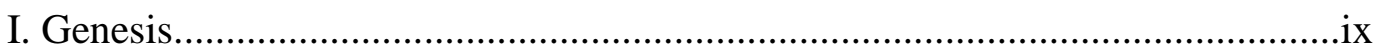

II. Publication......................................................................................

III. Contemporary Reception.................................................................

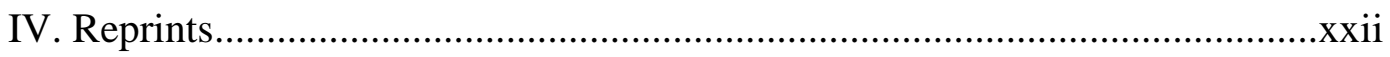

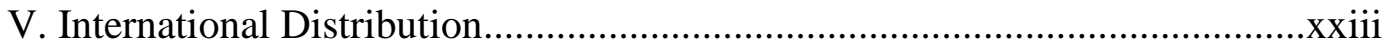

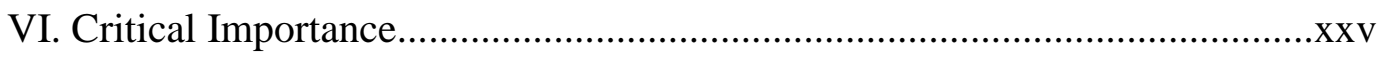

Text of Mercedes of Castile

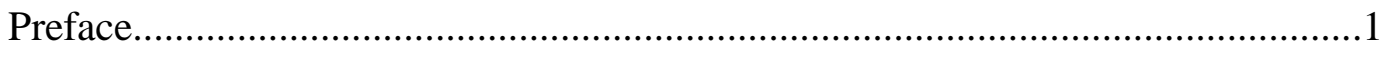

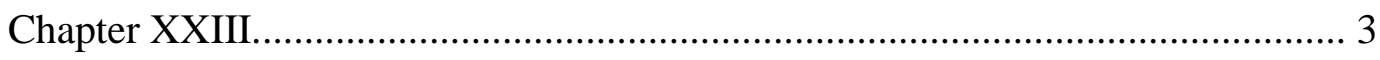

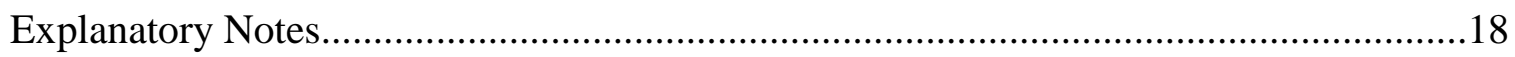

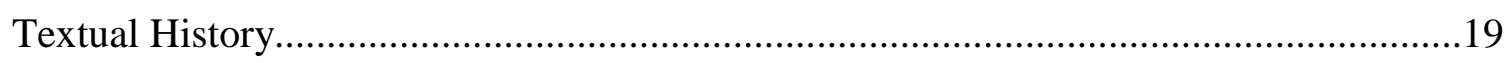

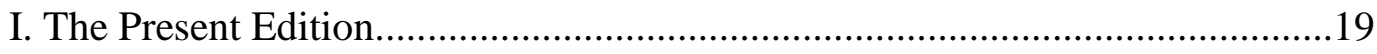

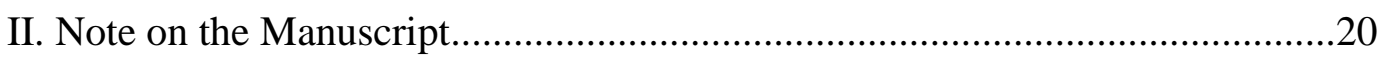

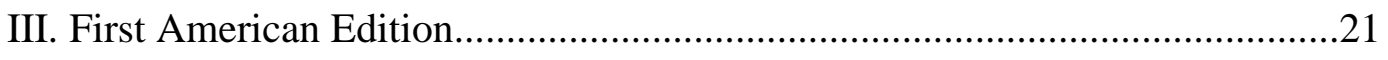

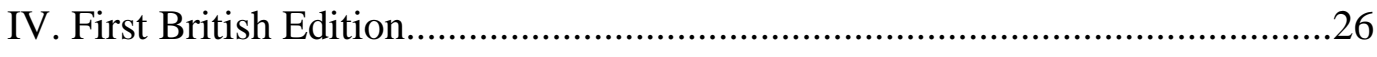

V. American Reprints and the 1859 Townsend Edition...................................29

VI. First French English-language Editions.................................................... 30

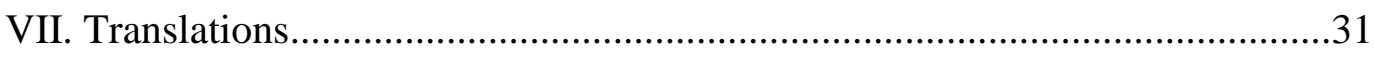

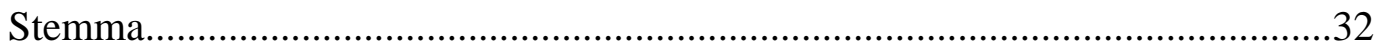




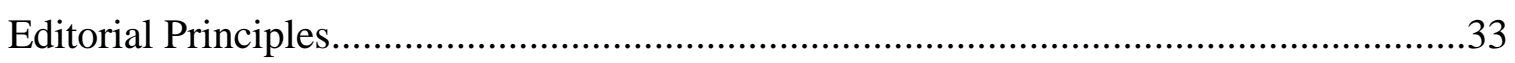

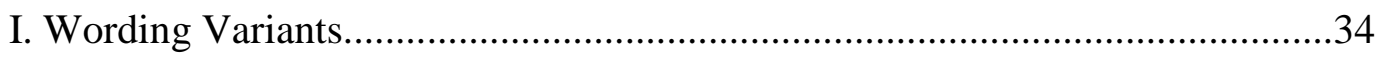

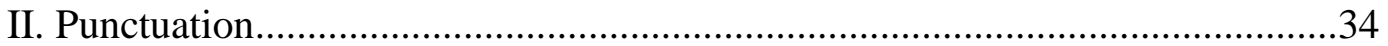

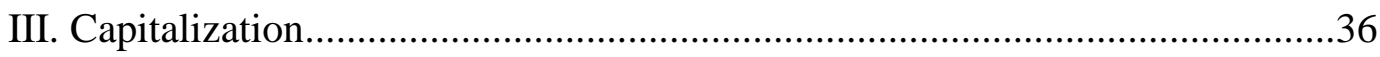

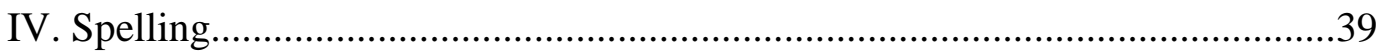

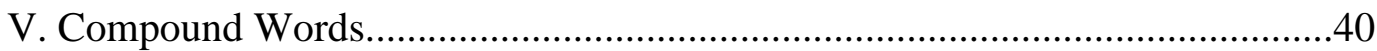

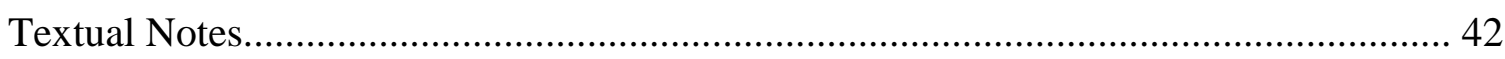

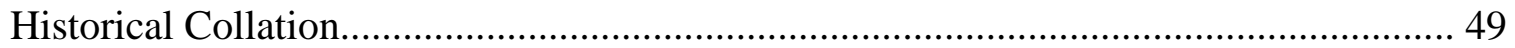

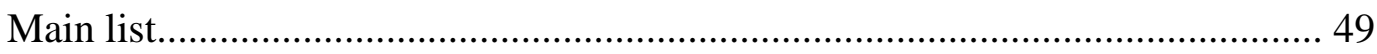

Alterations from the Manuscript to the First American Edition...........................58

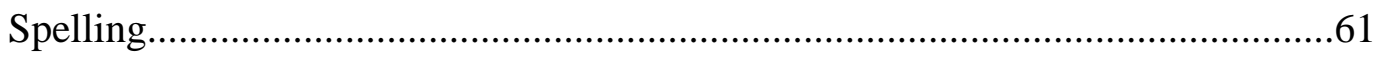

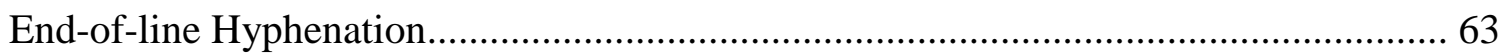




\section{Foreword}

James Fenimore Cooper is well known as the author of the Leatherstocking Tales, novels which set the character of Natty Bumppo against the backdrop of the American wilderness and various important historical moments in the colonial and founding era. He was also one of the most widely read authors of the early nineteenth century, and through his success helped to promote American literature beyond national borders. Cooper's works have, consequently, received a great deal of editorial attention. Thirtyone out of Cooper's thirty-six titles have been edited according to standards of modern textual criticism for "The Writings of James Fenimore Cooper" or are currently being prepared for inclusion in the series by members of the Cooper Society.

A novel of Cooper's which has not been edited but which is nonetheless a vital member of his corpus is Mercedes of Castile. Published in 1840, Mercedes of Castile is one of Cooper's least-known works. Most students of American literature do not realize that Cooper, along with other notable figures as Washington Irving and William $\mathrm{H}$. Prescott, wrote on the first voyage of Christopher Columbus. The subject was one of great fascination for Cooper, and his treatment of it constitutes a unique approach to historiography which, in addition to other issues such as race and gender relations, makes Mercedes of Castile a work worthy of further study. To enable this study and produce a reliable text which reflects Cooper's final intentions for this important novel, I have chosen to prepare a critical edition of the work.

In Mercedes of Castile, Cooper sets the first voyage of Christopher Columbus within the fictional story of Luis de Bobadilla, a Spanish nobleman, and Mercedes de 
Valverde, a Castilian heiress — both living in the court of Ferdinand and Isabella. Luis desires to marry Mercedes, but Isabella views his suit unfavorably because he has the reputation of a wanderer, having indulged in too many sea explorations. While the Spanish court is living in the freshly conquered Alhambra, the final stronghold of the Arab Muslim kings, Columbus comes to request the patronage of the Spanish monarchs. Mercedes prompts Luis to accompany Columbus and restore his honor, and it is partly Mercedes's interests that persuade Isabella to sponsor Columbus. Cooper retells Columbus's westward voyage, with Luis acting as the great navigator's confidante. When they reach Cuba, Luis meets the Indian princess Ozema, whom he and Columbus take back to Spain as a "specimen" to show Isabella. In the course of the voyage, Ozema falls in love with Luis, thinking he has plighted his troth to her by presenting a crucifix to her, when he only meant the gift to be a safeguard during a storm. Upon reaching Spain, Ozema discovers Luis is engaged to Mercedes and ultimately dies of illness and disappointment.

The present edition includes only Cooper's Preface and Chapter 23. The Preface is of particular interest for Cooper's sometimes whimsical, sometimes curmudgeonly, commentary on history. He declares that his work of romantic historical fiction delves deeper than the "slight and superficial researches" ${ }^{1}$ conducted by previous works on Columbus, and he attacks Irving for his apparently inconsistent treatment of nautical time in his The Life and Voyages of Christopher Columbus (1828). The Preface also includes commentary which firmly situates Mercedes in the context of Cooper's Press Wars, in which he sued multiple newspaper editors for libel. It is thus a fascinating glimpse not

\footnotetext{
${ }^{1}$ James Fenimore Cooper, Mercedes of Castile (present edition) 1.
} 
only into Mercedes, but into a tumultuous moment in the life of its author. Chapter 23 features Luis exploring Haiti, meeting Ozema, and defending her from a rival chieftain who wishes to kidnap her and make her his bride. The chapter is of interest because it shows, according to Cooper, "the first occasion on which the Spaniards had come to blows with the mild inhabitants of the islands they had discovered." ${ }^{2}$ The central feature of the chapter is the extensive description of Ozema, who is depicted as a doppelganger of Mercedes, so nearly does she resemble Luis's Spanish love.

The present edition is preceded by a historical introduction describing the development of the idea of Mercedes of Castile, its publication, its contemporary reception, and its critical importance. I have chosen to present a clear text, with a minimum of explanatory notes listed at the back of the text, so that it will be approachable both to scholars and general readers. The explanatory notes provide contextual knowledge which contemporary readers would have had, but which the modern reader may lack. It will thus enable readers to experience Cooper's text with as little distraction as possible while providing essential historical knowledge, thus approximating the original reading experience of Cooper's own readers. ${ }^{3}$ The apparatus includes the "Textual History," which is a discussion of the various stages of revision and corruption which Cooper's text has undergone, and textual notes explaining particularly important textual variants are to be found immediately after the textual history. Cooper's handwriting was especially prone to misreading during composition, and compositors freely changed his punctuation - to name only a couple ways in which his work was

\footnotetext{
${ }^{2}$ Present edition 15 .

${ }^{3}$ A considerable exception to this rule are the line numbers to the left of the text, which I would not include were I to publish an edition but do include here to facilitate review.
} 
altered against his wishes in the course of publication. By collating, or comparing word for word, the manuscript and the printed editions published during Cooper's lifetime, I traced these changes. Scouring publisher records and Cooper correspondence at the Beinecke Rare Book and Manuscript Library (Yale), the Historical Society of Pennsylvania, and the Albert and Shirley Small Special Collections Library (University of Virginia), I gathered details about Cooper's personal life and publishing practices. Guided by these discoveries, I analyzed each change in the text and determined which reading best represented Cooper's final intentions for Mercedes. Thus, the text of Mercedes of Castile which Cooper wished his readers to experience is presented for the first time ever in this edition.

In preparing this edition, I chose to edit without a copy-text, taking the majority of my readings from the author's holograph manuscript and the first American edition. The "Editorial Principles" provides a detailed account of my treatment of the different types of textual variants, such as wording, capitalization, punctuation, etc. The "Historical Collation" lists all variants between the manuscript and contemporary printed editions. These supplementary materials will provide interested readers with a thorough understanding of the origin and evolution of the text which they encounter in this edition. Another resource which I offer to the interested reader is my digital edition of the Preface and Chapter XXIII of Mercedes of Castile. I built the digital edition as my Rare Book School Fellowship project this year. It is useful in that it enables users to change between the texts of the manuscript, interpolated proof stages, and printed editions at any point while reading the text. It also includes diplomatic markup showing additions and 
deletions in the MS and proof stages, as well as color-coded variants. Readers interested in how often Cooper's punctuation was changed as opposed to his capitalization have merely to look for the appropriate colors to make the comparison. Lastly, if a reader is interested in a particular variant, clicking on that variant will produce a pop-over window with a list of all the readings of the different witnesses. The digital edition contains exactly the same information as this edition, but it enables the user to interact with the text differently: the metamorphosis of Mercedes is visible right in the reading text itself; history is but a click of the mouse away. The digital edition is hosted on GitHub and may be viewed at http://stephanie-kingsley.github.io/Mercedes/. 
Introduction

\section{$\underline{\text { I. Genesis }}$}

Cooper's interest in the history of Spain and the Spanish Colonies began long before he was inspired to write Mercedes of Castile. While still a teenager living in Cooperstown, Cooper became fascinated by the Venezuelan revolutionary Francisco de Miranda and his plot to overthrow Spanish rule in his country; Cooper even wished to accompany him to the Caribbean. Although this plan never came to fruition, as a sailor on the merchantman the Stirling Cooper later became acquainted with another sailor, Ned Myers, who had been one of Miranda's recruits to Santo Domingo. ${ }^{4}$ While in the service of the Stirling, Cooper spent time in the Spanish city of Almeria, a city with a long history of Roman and Moorish settlement, and biographer Wayne Franklin suggests that

Cooper's time on shore in Almeria may have fueled his interest in that country's history. ${ }^{5}$

As a writer Cooper continued to be fascinated by Spain, and when his longtime London publisher, Richard Bentley, suggested that he write a work on Christopher Columbus, Cooper responded with zeal. The previous year, Bentley had published William H. Prescott's history, Ferdinand and Isabella, which dealt with the reign of the famed Spanish monarchs, devoting two chapters to the first and second voyages of Columbus. In early October of 1839, while hard at work on his newest Leatherstocking Tale, The Pathfinder, Cooper received from Bentley "a handsome copy" of Ferdinand and Isabella to fuel his imagination. ${ }^{6}$ He would later credit this work for inspiring

\footnotetext{
${ }^{4}$ Wayne Franklin, James Fenimore Cooper: the Early Years (New Haven: Yale, 2007) 68, 77-78.

${ }^{5}$ Franklin 89-90.

${ }^{6}$ Cooper to Mrs. Cooper, 4 Oct. 1839, in Correspondence of James Fenimore Cooper, ed. James Fenimore Cooper (grandson), vol. II (New Haven: Yale, 1922) 39 (cited hereafter as Correspondence).
} 
Mercedes: "reading Prescott's capital work on Ferdinand and Isabella [has] excited a desire to treat it [the subject of Columbus]."7

Two weeks after receiving the book, on October 17 or 18, Cooper wrote to Bentley expressing his excitement at the idea of Columbus, and in this letter, Cooper reveals his thoughts on his anticipated work: "Such a book, however, must be better than common; written with care, and a little in the 'Ercles vein. ... I really like the subject, and have an ambition to touch the heroics." ${ }^{8}$ Cooper's interest in "the heroics" reveals the author considering how he wants to treat Columbus and how much he wants the focus of the work to be on the navigator himself. Columbus had been much celebrated in Prescott's work, as well as in Irving's Life and Voyages of Columbus, another work Cooper was inspired by and responding to.

Cooper clearly wanted his work to have historical value, but he also longed to inhabit his fictional sphere, and the murmur of conflict which arose within Cooper and his budding novel is evident in his correspondence. Writing to Bentley of his vision for the novel in November, Cooper says, "Such a book ought to be better than common; more accurately written, and more carefully elaborated.... my desire is to make of the Columbus a high wrought and standard fiction...." 9 This letter reveals a conflict within Cooper with respect to fiction and history. Ferdinand and Isabella was a history, and Cooper wanted his book to be "accurately written" but also "carefully elaborated" and a "standard fiction." Herein arose within the new work a tension between the factuality of

\footnotetext{
${ }^{7}$ Cooper to Bentley, 12 Nov. 1839, in The Letters and Journals of James Fenimore Cooper, ed. James Beard, vol. III (Cambridge: Belknap, 1964) 443 (cited hereafter as Letters).

${ }^{8}$ Cooper to Bentley, 17 or 18 Oct. 1839; Letters III, 433-34.

${ }^{9}$ Cooper to Bentley, 12 Nov. 1839; Letters III, 443.
} 
history and imagination of fiction. Cooper's comments later in the letter on the subject of the title further reflect his inclination towards the fictive in this new work: "I do not intend to call the new book 'Columbus.' There must be a love story, of course, and that will affect the name. I only intend that the voyage shall be a leading point in the work."10 By December, Cooper referred to the novel as "a tale connected with the first voyage of Columbus [my italics]," revealing how much his emphasis had moved towards romantic fiction rather than history. ${ }^{11}$ Cooper's focus a few months into conceptualizing the novel was not Columbus at all; rather, he saw the navigator and his voyage as a backdrop for romance. This change of focus, however, did not agree with his publishers. Throughout the publication process, Cooper would battle both Lea \& Blanchard and Bentley for a title other than "Columbus," which he considered "a miserable misnomer and a pure catch penny." 12

In December 1839 Cooper was finishing up The Pathfinder, ${ }^{13}$ and he may have begun work on Mercedes sometime that winter. ${ }^{14}$ By March Cooper was hard at work on the new novel, writing to his attorney, James Ogden, of "a good deal of literary work." He reported in this letter that Mercedes was "not quite half done, but so far I think it pretty good, the love story being rather ingeniously brought in." ${ }^{15}$ Cooper finished drafting Mercedes that autumn amid a flurry of legal and family affairs. On August 2, Cooper wrote of his busy life to Robert Hare, providing an update on Mercedes, his libel suits, his son's departure for college, and his daughters' upcoming trip to Niagara, finally

\footnotetext{
${ }^{10}$ Cooper to Bentley, 12 Nov. 1839; Letters III, 444-45.

${ }^{11}$ Cooper to William Branford Shubrick, 6 Jan. 1840; Letters IV, 9.

${ }^{12}$ Cooper to Mrs. Cooper, 28 Oct. 1840; Correspondence II, 431.

${ }^{13}$ Cooper to Mrs. Cooper, 19 Dec. 1839; Correspondence II, 408.

${ }^{14}$ Cooper to William Branford Shubrick, 6 Jan. 1840; Letters IV, 9.

${ }^{15}$ Cooper to James De Peyster Ogden, 23 Mar. 1840; Letters IV, 26-27.
} 
concluding, "I never had so much to do, in so short a time." ${ }^{16}$ Cooper finished revising his manuscript in mid October onboard the Macedonian en route to Philadelphia to attend the 1840 presidential election between Martin Van Buren and William Henry Harrison. He worked diligently, even passing up a yacht party, "in order to get on with Mercedes" ${ }^{17}$ _likely in response to frantic requests from Lea and Blanchard for more manuscript: We are quite disappointed in not hearing from you with more M.S. The time is passing away without making the progress we calculated on + we fear that the season will get by unless you make an exertion to put the remainder of the M.S. in our hands. ${ }^{18}$

That November, when he returned from Philadelphia to his family in Cooperstown, Cooper brought a copy of the newly printed book. He assured his wife that his trunk would include Mercedes, saying, "There will be very few books. Mercedes, however, will be among them." ${ }^{19}$ The closing to this also letter reveals his affection for his wife, as well as, implicitly, the completed novel: "God bless you all, and rest assured of my tenderest love-you are my Mercedes." 20

\section{$\underline{\text { II. Publication }}$}

While writing Mercedes, Cooper also busily planned for its publication and closely oversaw the printing of the first American edition by Lea \& Blanchard. In the late 1830s, Cooper's popularity was waning. Additionally, because of the publishing industry's shift to New York at this time, Lea and Blanchard had begun focusing

\footnotetext{
${ }^{16}$ Cooper to Robert Hare, 2 Aug. 1840; Letters IV, 52.

${ }^{17}$ Cooper to Mrs. Cooper, 15 Oct. 1840; Correspondence I, 425-26.

${ }^{18}$ Lea and Blanchard to Cooper, 18 Oct. 1840; MS: Collection of American Literature, Beinecke Rare Book and Manuscript library, Yale University (cited hereafter as YCAL).

${ }^{19}$ Cooper to Mrs. Cooper, 7 Nov. 1840; Letters IV, 101.

20 ibid.
} 
increasingly on medical publishing rather than fiction. By 1838, Cooper had his doubts of their continuing to publish his work, writing to his wife, "I think my connection with Carey draws near a close. I do not expect that he will publish either Home-As-Found or the Naval History." ${ }^{21}$ Nevertheless, on May 18, 1840, Lea and Blanchard signed a contract with Cooper to publish a work in two volumes, yet untitled, "on the subject of the voyages of Columbus to America." The contract permitted them to print at least 5000 copies and gave them exclusive copyright on the work for two years. Cooper was to have the manuscript ready for printing by September, and he would receive $\$ 2500$ in two payments for the work. ${ }^{22}$

Mercedes went to the printer, Isaac Ashmead, in early June, ${ }^{23}$ with stereotype plates ordered from John Fagan. ${ }^{24}$ While finishing the manuscript, Cooper had early portions of the book in press, and, upon his arrival in Philadelphia, Cooper personally oversaw the novel's printing. The printers set the book directly from his holograph manuscript, and the author edited the printed proof sheets-likely more than one set, as Lea \& Blanchard's cost book reports paying $\$ 2.00$ for extra proofs. The cost book gives an idea of the labor involved in printing the book: 513.20 hours for initial composition with an additional 173 hours to make alterations in the proofs. ${ }^{25}$

\footnotetext{
${ }^{21}$ Cooper to Mrs. Cooper, 25 May 1838; Correspondence I, 379.

${ }^{22}$ Contract, 18 May 1840; MS: Lea and Febiger Archives, Historical Society of Pennsylvania, Philadelphia (hereafter cited as HSP).

${ }^{23}$ Cooper to Bentley, 6 June 1840; Letters IV, 42.

${ }^{24}$ Lea \& Blanchard ledger, pg. 33; MS: HSP.

${ }^{25}$ Lea \& Blanchard cost book; MS: HSP. These numbers appear to be typical for a Cooper novel: the cost book records 141 hours for corrections in The Pathfinder. Compare both these numbers, however to the number of hours spent correcting Cooper's Naval History: 318 hours. This book does not appear to have been significantly longer. These numbers may indicate that in his revision process, Cooper saw Mercedes as a novel and treated it as one-despite the fact that, it being a historical fiction, there could have been just as many factual errors to fix as in the Naval History.
} 
On November 21, the New-Yorker printed an excerpt of the novel, "having been favored by the publishers with a copy of the work in advance of its public appearance." This excerpt was of Chapter 5, and was entitled "The Court of Castile in the Days of Christopher Columbus." 26 Three days later, on November 24, the complete Mercedes of Castile was finally presented to the public. The first American edition was published in two hardback volumes, bound in purple cloth with paper labels, under the title of Mercedes of Castile, or, the Voyage to Cathay. Production costs to print and bind the 5000 copies totaled $\$ 720.39$, with an additional $\$ 10.50$ for the stereotype plates. $^{27}$

While Lea \& Blanchard prepared the first American edition of Mercedes in Philadelphia, Richard Bentley was at work on the first British edition in London. In fact, Cooper had signed a contract with Bentley long before he signed with Lea \& Blanchard. In November of 1839, Cooper was already negotiating with Bentley on the price for the work. On November 8, Bentley submitted a proposal to pay Cooper 500 pounds for the copyright in the U.K. for The Pathfinder (minus 200 pounds in consideration of the loss Bentley had suffered on account of the Naval History's poor sales in England), and 500 pounds for the copyright in the U.K. for the work on Columbus. ${ }^{28}$ Cooper acceded to these terms, with, however, a difference of 50 pounds remaining unresolved between him and Bentley well into the book's printing. ${ }^{29}$

\footnotetext{
26 "The Court of Castile in the Days of Christopher Columbus," The New-Yorker (21 Nov. 1840): 145.

${ }^{27}$ Lea \& Blanchard ledger, pg. 33; MS: HSP. These numbers are also comparable to those for The Pathfinder.

${ }^{28}$ Bentley to Cooper, 8 Nov. 1839; MS: YCAL.

${ }^{29}$ Cooper to Bentley, 29 Aug. 1840; Letters IV, 61. Cooper requested to bill Bentley for 100 pounds on Mercedes, saying that the bill left a 50-pound balance "according to [Cooper's] offer," though he acknowledged that the point had never been settled between them. Bentley wanted the amount on Mercedes to be 50 pounds less to help defray costs from Cooper's Naval History, a failure in England.
} 
As was Cooper's usual practice, he supervised the printing of the edition where he was present - in this case, Philadelphia — and then sent proof sheets to other publishers, requesting that they set their editions from the printed sheets. For Bentley, Cooper also forwarded the manuscript, which Bentley needed to back his copyright on the novel in the British courts. On August 29, Cooper wrote to Bentley, By President, steamer, I send you not quite half of Mercedes of Castile; the work [is] in press, and will be forwarded as soon as possible. I send manuscript as far as sheets, but you will correct from last, as a matter of course. A Duplicate goes by London Ship.

Cooper's parting comment tells Bentley to "[d]epend on having time, and expect to publish in all October." ${ }^{30}$ Despite Cooper's confidence, however, not all went smoothly with these transactions. On Saturday, November 7, he wrote to his wife that he would be unable to make it home as early as he wished for the winter, "[o]wing to an unlucky mistake with the manuscript." ${ }^{31}$ The "unlucky mistake" likely referred to a mishap in the shipping of the manuscript; Bentley, as of November 13th, still had not received it: I have been most anxiously expecting for the last three weeks the remainder of the novel Mercedes of Castile, of which even at this date 13th November I have had no tidings. I trust that no accident has happened to the manuscript in the course of its being transmitted to me. ${ }^{32}$

Cooper appears to have resolved this problem, as he sent the last of the MS on the steamship President on November 11, writing the concerned Bentley to inform him of

\footnotetext{
30 ibid.

${ }^{31}$ Cooper to Mrs. Cooper, 7 Nov. 1840; Letters IV, 101.

${ }^{32}$ Bentley to Cooper, 13 Nov. 1840; MS: YCAL.
} 
this on the 10th and instructing him to "publish as soon as possible, as I have accidentally been delayed in printing. ... L \& B, will publish Mercedes about the time you can." ${ }^{33}$ Bentley's concerns stemmed from the fact that he needed to print before or at the same time as Cooper's American publishers in order to have copyright in the United Kingdom; the majority of Cooper's correspondence with Bentley deals with this very problem. Thus, the delay in shipping the manuscript well into November was a point of great anxiety for Bentley. Nonetheless, the manuscript and sheets arrived in England, and the book was printed, this time in three volumes. It was announced as "just ready" on October 24 and November 21, and as "now ready" on December 5 in the Literary Gazette. ${ }^{34}$ Bentley officially published Mercedes on December 5, printing 1500 copies. ${ }^{35}$

\section{Contemporary Reception}

When Mercedes arrived in bookshops that winter, the circumstances were already inauspicious for its success. Embroiled in his well-publicized lawsuits, having become more politically outspoken in his novels than was palatable to his readers and reviewers, and having strayed from the subject matter that had made him famous (that of the Leatherstocking Tales), Cooper had sunk in popularity. Both his American and English publishers had failed to make a profit on the several novels leading up to Mercedes. As

\footnotetext{
${ }^{33}$ Cooper to Bentley, 10 Nov. 1840; Letters IV, 102.

${ }^{34}$ Jacob Blanck, Bibliography of American Literature, vol. 2 (New Haven: Yale, 1957): entry 3893.

${ }^{35}$ Publisher's list, in The archives of Richard Bentley \& Son 1829-1898, British Library collection, reel 39, vol. 78 (microfilm published by Chadwick-Healy, 1976) 50. The entry lists Mercedes as having been published on 5 Dec. 1840, for "31/6" in "3 vols post 8vo." Bentley is listed as the printer, although the list shows that he also frequently commissioned print jobs to others, such as a Schulze, Brettell, Nichols, Clowes, and Taylor. It is interesting that Bentley only printed 1500 copies, compared to the 4000 initially printed by Lea \& Blanchard. It may be that this was due to increased expense of producing a three-volume work, or that Bentley intentionally ordered a smaller print run out of concern that the book would not sell well. A survey of the publisher list entries would be needed to get an idea of Bentley's typical practices and why he might have printed so few copies of Mercedes.
} 
previously mentioned, Cooper doubted his continuing in business with Lea \& Blanchard, ${ }^{36}$ and even Bentley, with whom Cooper had forged a strong author-publisher relationship over many years, was offering Cooper less and less money for new books to compensate for losses on earlier ones. Mercedes became a part of this general downward trend, and, despite Cooper's beliefs that the book would "hit" with the public, it proved a failure, commercially and with critics. ${ }^{37}$ Both publishers reported having problems selling their first print runs of the novel. Bentley wrote in January that the sales "leave [him] a loser to some amount," 38 and as of March, the demand in London for Mercedes stopped altogether. ${ }^{39}$ Lea $\&$ Blanchard reported sales of no more than 1,500 or 1,800 copies of 4,000 they printed, saying, "Every where we find, in place of being able to draw for the money, that the work is on hand." ${ }^{40}$ Both publishers asked for financial consideration on the part of Cooper, due to their heavy losses: Lea \& Blanchard asked him to consider remitting them the money paid him for the 1,000 copies they did not print $^{41}$ and Bentley requested to put the aforementioned debated 50 pounds toward Cooper's pay for The Deerslayer. ${ }^{42}$

The likely causes for this book's failure are themselves a subject of peculiar interest. Bentley partially attributed Mercedes's lack of success to its name, writing, "It was unfortunate that you enjoined me to preserve your title; which gave no interest of an extraordinary bent to your work. On the first appearance of a book a title has somewhat

\footnotetext{
${ }^{36}$ Cooper to Mrs. Cooper, 25 May 1838; Correspondence I, 379.

${ }^{37}$ Cooper to James De Peyster Ogden, 23 Mar. 1840; Letters IV, 26, 27.

${ }^{38}$ Bentley to Cooper, 7 Jan. 1841; MS: YCAL.

${ }^{39}$ Bentley to Cooper, 6 March 1841; MS: YCAL.

${ }^{40}$ Lea and Blanchard to Cooper, 8 Feb. 1841; MS: YCAL.

41 ibid.

${ }^{42}$ Bentley to Cooper, 7 Jan. 1841; MS: YCAL.
} 
to do with its favorable reception." ${ }^{43}$ Lea \& Blanchard suggested the problem being the nature of the work itself: "we stated to you our disappointment in the character of the work before publication it being different from what you stated previously to finishing it." ${ }^{44}$ Perhaps this difference had to do with Cooper's eventual move away from a focus on Columbus (indeed, the contract with Lea \& Blanchard was for a work on Columbus's voyage) to the much greater focus on the romance between Luis, Mercedes, and Ozema.

A look at the contemporary reviews of the book upon its release reveals a number of elements which either repulsed or simply confused readers. The novel did receive some positive remarks. For instance, Godey's Lady's Book called it "one of the best novels he has produced yet." The magazine clearly enjoyed the novel, not heralding it for great complexity or depth, but for being a clean, pleasurable read: "The plot of the tale is simple, but it is managed with much skill, and the characters are conceived and drawn with great ability of portraitism." The novel was also appreciated for its management of the historical content. Graham's Review applauded Cooper for the way he condensed the many events of Columbus's voyage into a readable narrative. The magazine even goes so far as to say that Cooper's descriptions of some of the great moments of Columbus's story, such as his departure from Spain and then hasty recall to the court, "are worthy of the best passages of the Pioneers, the Water-Witch, or the Last of the Mohicans." However, for every admiring comment on an element of the novel, there is another criticizing that very same point. For instance, although Godey's praises Cooper's characterization, reviewers G. \& C. Carvill, writing for the Ladies' Companion, call those

\footnotetext{
${ }^{43}$ Bentley to Cooper, 7 Jan. 1841; MS: YCAL.

${ }^{44}$ Lea \& Blanchard to Cooper, 8 Feb. 1841; MS: YCAL.
} 
same characters "feebly drawn." Graham's, according to its review, did not even look for characters, "for that is not Cooper's forte." Meanwhile, in contrast to Graham's approval of Cooper's historical descriptions, Godey's calls the book "only a compound of historical incidents already known to every one who is in the least acquainted with the life of the celebrated navigator." ${ }^{45}$

A simple explanation might be that the critics and the readers wanted more Leatherstocking Tales, and indeed, the Lady's Companion would open its review of The Deerslayer, Cooper's next novel after Mercedes, saying, "We are happy to meet Mr. Cooper once more in his proper sphere delighting and instructing by his beautiful delineations of the characters and scenery of his own 'free land."'46 Still, I suggest that what most baffled readers was the peculiar way in which Cooper uses Columbus as a backdrop for the fictional plotline. The novel's purpose, arguably, is to write the 'real' history pertaining to the Spanish conquest of the Caribbean-not that which celebrates Columbus, but an alternative history which takes a moment to delve deeper into the trauma wreaked upon the natives of the islands in the process of meeting the Spaniards, suffering their attempts at conversion, and undergoing colonization. Cooper's deliberately unsubtle incorporation of Luis's adventures into the otherwise stable retelling of Irving's account of Columbus — while being the kernel of the novel—was not something readers or critics were prepared to encounter. In fact, Graham's review selects this conflict between the genres of history and novel as its chief point of criticism: "As a history, this work is invaluable: as a novel, it is well nigh worthless." Furthermore, it is

\footnotetext{
${ }^{45}$ Godey's Lady's Book (Jan 1841): 46; Graham's Lady's and Gentleman's Magazine (Jan 1841): 47; The Ladies' Companion (Oct 1841): 310.

${ }^{46}$ The Ladies' Companion (Jan 1841): 148.
} 
clear that the writer of Graham's was looking for-like Irving's Life of Columbusanother work which focused on Columbus: "It is but justice to the author to say that the necessity of adhering closely to fact in his romance, is the true secret of its want of interest; for how could any hero, no matter whom, awaken our sympathy strongly, so long as Columbus figured in the same narrative?" 47 In addition to suggesting that the reviewer's favorite part of the work was Columbus himself, this comment pinpoints the reason why Mercedes fails to deliver as brilliant and gripping a plot as some of Cooper's other novels: as long as it is a faithful history, its ability to be a vivid novel is curtailed. Thus, the tension between history and fiction which is evident in Cooper's earliest comments on Mercedes carried over into the final published novel and perplexed readers.

Entirely apart from the novel itself, however, the Press Wars in which Cooper was engaged did not help the success of Mercedes. At the time, Cooper was actively pursuing several libel suits against various newspaper editors - who had published articles claiming Cooper had written The Pioneers intending it to be about himself and his family in Cooperstown. ${ }^{48}$ Mercedes became the target of vindictive reviews by these editors' papers, and Cooper triggered even more such reviews by his belligerent remarks in the preface to Mercedes. Speaking of the press, for instance, Cooper writes, "we state truths, with a profession of fiction, while the great moral caterers of the age state fiction with the profession of truth." 49 This is a clear reference to the libel of which Cooper accused several presses. Cooper also makes explicit fun of critics, saying that they are "more apt

\footnotetext{
${ }^{47}$ Graham's Lady's and Gentleman's Magazine (Jan 1841): 47.

${ }^{48}$ For an account of Cooper's Press Wars, see James Beard's introduction to the Writings of James Fenimore Cooper edition of The Deerslayer, ed. Lance Schacterle (Albany: State University of New York, 1987) xxvii-xxviii.

${ }^{49}$ Cooper, Mercedes of Castile (present edition) 1.
} 
to wink at these minor inconsistencies [such as Irving's using both nautical and standard time in his Columbus], than to pass over an error of the press, or a comma with a broken tail. As we wish to live on good terms with this useful class of our fellow creatures, we have directed the printers to mis-spell some eight or ten words for their convenience." 50 These comments likely annoyed even those presses with which Cooper was not at war, such as Godey's Lady's Book, which writes at the end of its otherwise positive review, "We wish Mr Cooper had spared us the flippant preface." ${ }^{51}$ When the preface met the eyes of New World Review editor, Park Benjamin, who was himself being sued, it prompted not one but two reviews which had more to do with the libel suits than they did with the novel. On December 5, in response to the passage quoted above from the Preface, the New World Review replied, "Meaning us, you perceive, dear public. Delicate, isn't it? Neatly hit off. Courteous withal, modest, and in good taste." ${ }^{52}$ The review went to execute more attacks on Cooper, practically ignoring Mercedes of Castile, of which, by its own account, it had only read the Preface. A week later, the magazine issued another so-called review on Mercedes: "We have taken it in hand three several times with the desperate resolution of reading it, but the thing is impossible - the task is beyond our power. We have not read it. We cannot read it." ${ }^{53}$ The reviewer concluded that, not having read Mercedes, he could not make any comments on its quality, and therefore would not fall victim to libel. Any readers familiar with Cooper's affairs at the

\footnotetext{
${ }^{50}$ Cooper, Mercedes of Castile (present edition) 1.

${ }^{51}$ Godey's Lady's Book (Jan 1841): 46.

${ }^{52}$ The New World (5 Dec 1840): 429.

${ }^{53}$ The New World (12 Dec 1840): 447.
} 
time could not have missed the personal ire at the bottom of these reviews, but, notwithstanding, the reviews did not help Mercedes's sales or reputation.

To conclude this account of Mercedes' reception, Cooper's novel set against the voyage of Columbus is not one of his most thrilling or comprehensible works. Still, it is not without interest, as several of these reviews suggested. I believe it suffered from a combination of audiences not knowing how to read its interweaving of history and fiction, and presses wishing to repay Cooper for their legal entanglements.

\section{$\underline{\text { IV. Reprints }}$}

Mercedes was never published again in the United States or England in its own right. It did, however, live on in the many American reprints of Cooper's collected works. Lea \& Blanchard released a collected works edition in $1843,{ }^{54}$ and may have had plans for an earlier edition, in which Mercedes would have been included. The

Bibliography of American Literature reports unsold sheets of Mercedes, probably as part of the collected works, labeled on the back, "Lea and Blanchard Have Commenced The Re-Issue... Of J. Fenimore Cooper... December 1842." ${ }^{55}$ This edition does not appear to have been published; no libraries report having such an edition on WorldCat.

In 1844 Cooper signed a contract with Lea \& Blanchard transferring the plates and copyright for several of his novels, including Mercedes, to Cooper. ${ }^{56}$ These Cooper sold to Burgess \& Stringer, a publishing house that specialized in inexpensive reprint editions. In 1849 Lea \& Blanchard sold Burgess \& Stringer the plates and copyright for

\footnotetext{
54 The American Antiquarian Society has an 1843 edition, but they are lacking the volume with Mercedes. ${ }^{55}$ BAL 3893; these sheets are housed at Harvard U. I was unable to examine them in the preparation of this edition, but future work would certainly involve collation of these sheets against the other extant witnesses. Given the fact that all reprints of the novel were printed from the plates made from the first American edition, it is likely these, too, were reprints, but one would have to collate them to ascertain this. ${ }^{56}$ Contract between James Fennimore Cooper and Lea \& Blanchard, 29 Nov. 1844; MS: HSP.
} 
its remaining novels. ${ }^{57}$ The firm would issue numerous reprints of the collected Cooper's Works throughout the 1840s and '50s under the imprints Burgess \& Stringer, Stringer \& Townsend, W. A. Townsend \& Co., and James G. Gregory. These reprints were all printed from the stereotyped plates made from the first American typesetting, and the firm would not reset Mercedes until 1859, when it published an edition of the complete Works with frontispieces by F. O. C. Darley.

\section{$\underline{\text { V. International Distribution }}$}

Despite Mercedes' dubious reception in the United States and England, it nonetheless was distributed throughout Europe, and the French, German, and Spanish translations published in 1841 show Mercedes, and Cooper himself, to have been of greater interest in that part of the world. The work first appeared in Paris in an Englishlanguage edition published by A. \& W. Galignani and Baudry's European Library. These two houses apparently published Mercedes jointly, as their editions are from the same setting of type, on the same paper, and by the same printer. That same year, two French translations appeared, one translated by E. de la Bédolliere and published by Gustave Barba in Paris, and the other by translator A. J. B. Defauconpret-who had also translated many of Cooper's earlier novels — and publisher Charles Gosselin. The two French translations in the same year reveal a concern with making the work available to a greater body of readers in France, and the Defauconpret translation was also published in Brussels. Two German editions appeared in 1841 in Frankfurt and Stuttgart, as well as the first Spanish edition, which was translated by Pedro A. O'Crowley and published in three volumes in Cádiz. The work was translated into Spanish again in 1863, and reprints

\footnotetext{
${ }^{57}$ Contract between Lea \& Blanchard and Stringer \& Townsend, 21 Sept. 1849; MS: HSP.
} 
as late as 1907 and 1952 show it to have been of special and continuing interest in that country. Mercedes was also translated and published in Mexico in 1852 as a part of the Biblioteca española, under the title Cristóbal Colón.

The design and features of the French and Spanish editions bear out Cooper's ongoing popularity in Europe at a time when his reputation was waning elsewhere. A third Brussels edition (1841) ${ }^{58}$ of the Defauconpret translation features a historical and biographical introduction by Charles Romey, who praises Cooper for his brilliant depiction of the sea, his portraits of the American wilderness, and his position as the founder of American literature. He also comments on Cooper's popularity in France: "Many editions of his works, sought eagerly, testified to its popularity among us, and his name is now equally familiar and dear to all friends of literature, as those of our own great national writers" (my translation). ${ }^{59}$ These translations also show greater care in preparation in that - unlike the American and British editions - the publishers included illustrations in their first editions. The first Spanish edition included numerous lithographs, and the Gosselin French edition, three intaglio prints. These illustrations show how Cooper was still popular enough to merit this added expense. They are also fascinating because they reveal which parts of the novel publishers thought people would be most interested in seeing depicted. The following scenes are a few examples of those depicted in the first Spanish edition: Isabella and Beatriz talking about their suitors, a portrait of Columbus, Columbus departing from Granada with the Alhambra in the background, the lovers embracing, the priest blessing Columbus before he sets sail,

\footnotetext{
${ }^{58}$ I have found no references to a second Brussels edition.

${ }^{59}$ Charles Romey, introduction, Mercédès de Castille by James Fenimore Cooper, trans. A.-J.-B. Defauconpret (Brussels: Société Belge de Librairie, 1841) 13.
} 
sighting land, a portrait of Ozema, and Luis fighting off Caonabo's warriors - the event included in the current edition. The French edition frontispiece features Luis chatting to Columbus on the deck of the Santa María, and its two illustrations are of Luis meeting Columbus the day the Spaniards take the Alhambra, and Ozema throwing herself before Luis to save him from the Carib warriors. These illustrations show what the French and Spanish still recognized as iconic historical images on the one hand, and scenes they found interesting within the fictional parts of the novel; already, their comprehension of Cooper's novel appears to have been greater than that of his American and British readers. Both the historical and imaginary were thought worth visualizing, which aptly reflects the way Cooper seamlessly weaves together history and romance in Mercedes of Castile. $^{60}$

\section{$\underline{\text { VI. Critical Importance }}$}

Mercedes of Castile is of interest to readers and scholars for several reasons.

First, the novel is important in that in it Cooper takes for his subject an earlier historical moment than any he had previously treated; from this perspective, Mercedes might be considered to be the novel that begins Cooper's historiography of the Americas. Thus, anyone interested in Cooper's treatment of the progress of population of the American frontier might view Mercedes of Castile as the first installment; indeed, Cooper appears to have considered it in this light himself. He certainly saw the events of Mercedes as marking the beginning of strife between the Native Americans and the white colonizers,

\footnotetext{
${ }^{60}$ A curious detail which I wish to point out is that in the illustration of Ozema in the first Spanish edition, the princess is presented from the torso up, with her name printed below-in the exact manner as the portrait of Columbus. This choice collapses the distinction between history and fiction, Columbus being a historical figure while Ozema springs purely from Cooper's imagination.
} 
and even though Mercedes, strictly speaking, deals with Spanish colonization, Cooper clearly has the Native Americans of North America in mind as well, as his footnote in Chapter 24 indicates:

The mild aborigines, who were numerous and happy when discovered, were literally exterminated by the cruelty of their new masters [the Spanish].... Toward the middle of the sixteenth century, it is said that two hundred of the aborigines were not to be found in the island, although Ovando had decoyed no less than forty thousand from the Bahamas, to supply the places of the dead, as early as $1513 ! \ldots$ All that has said of the influence of the white population of this country, as connected with our own Indians, sinks into insignificance, as compared with these astounding facts. $^{61}$

In this note, Cooper implicitly compares the Indian Removal in the United States, which would be fresh in the minds of his readers (the Cherokee Trail of Tears having just occurred in 1838), with the Spanish genocide in the Caribbean. Whether Cooper is being serious or deliberately provocative in deeming the offenses of the United States less egregious than those of Spain, is difficult to say, but the note does emphasize the fact that Cooper has not forgotten his own country's history while dealing with the history of the Caribbean and Spain; in fact, his comparison of the two suggests them to be very much a part of one continuous pattern.

\footnotetext{
${ }^{61}$ James Fenimore Cooper, Mercedes of Castile (New York: Townsend, 1859) 408 (hereafter cited as Townsend).
} 
Perhaps what is equally surprising, and in my opinion, all the more evidence that Cooper sees various colonized peoples as reflecting the plights of other such peoples, is the way the author draws parallels between the Spaniards' ousting of King Boabdil from the Alhambra — and by extension the restoration of Christianity to Spain — and Columbus' and Isabella's hopes of colonizing and converting the people of the New World. This idea is brought to bear the most vividly when Luis gives Ozema a turban stolen from an Arab adversary during the Reconquista:

In one of his onsets against the Moors, he had brought off a turban of rich but light cloth, and he had kept it as a trophy... This turban was on his head, at the moment he entered the apartment of Ozema, and overcome with the delight of finding so unexpected a resemblance, and, possibly, excited by so unlooked-for an exhibition of feminine loveliness, he gallantly unrolled it, threw out the folds of rich cloth, and cast it over the shoulders of the beautiful Ozema, as a mantle. ${ }^{62}$

Just as the Spaniards triumphed over the Muslims in Spain, so will they overcome Ozema's people; and just as the Reconquista enabled Isabella to restore Christianity to her country, so Luis' romantic ensnarement of Ozema enables him to convert her to Christianity. (Ozema converts in the end with the purpose of becoming Luis' wife, only to find out that because he is already married to Mercedes, he cannot marry her.)

Not only is Mercedes a work of significance for postcolonialist scholars, it would also make a fascinating — albeit at times frustrating — study for critics interested in gender and feminist studies. Cooper relegates Ferdinand to the sidelines of the story, keeping

\footnotetext{
${ }^{62}$ Present edition, pg. 8.
} 
Isabella firmly in the limelight. Indeed, it is arguably women who run the Spanish court. Isabella has her male advisers, but ultimately she discusses her major decisions with her bosom friend Beatriz de Bobadilla, and even includes the young Mercedes in her deliberations: Mercedes's ardent wish for Luis to have an opportunity to prove himself ultimately spurs Isabella to consent to sponsor Columbus. Thus, women are the forces powering the discovery of the Americas and their colonization.

At the same time, the women in Mercedes are all uniformly beautiful and pure, and are made interchangeable to some degree. This should come as no surprise, as Cooper is not particularly distinguished for writing round female characters - though he does not hesitate from bestowing upon Ozema a "well rounded form." ${ }^{63}$ Still, the effect is especially striking in Mercedes of Castile, and it is the most evident in the way Cooper makes Ozema and Mercedes into doppelgangers. His doubling of two women-one dark, one light — is similar to Edgar Allan Poe's pairing of Ligeia and Rowena, and it would not be going too far to draw comparisons between the way the two male protagonists, Luis and the Poe narrator, see one woman in the face of a completely different woman:

[Ozema's] cheeks were flushed, her eyes became as brilliant as ornaments of jet, and the teeth that were visible between lips like cherries, resembled rows of ivory. We have said that the eyes of Ozema were black, differing in this particular, from the deep-blue melancholy orbs of the enthusiastic Mercedes, but still they were alike, so often uttering the same feelings, more especially touching matters in which Luis was concerned. More than

\footnotetext{
${ }^{63}$ Present edition, pg. 7.
} 
once, during the trial of strength, did the young man fancy that the expression of the rapture which fairly danced in the eyes of Ozema, was the very counterpart of that of deep-seated delight which had so often beamed on him, from the glances of Mercedes in the tourney; and, at such times, it struck him that the resemblance between the two was so strong, as - after some allowance had been made for dress and other sufficiently striking circumstances - almost to render them identical. ${ }^{64}$

Lastly, Cooper presents his fictional women, Mercedes and Ozema, as inhabiting a suppressed history — undiscovered by Prescott and Irving, and only to be rediscovered and given life by Cooper. In the penultimate chapter of the novel, in which Mercedes confronts Luis about his fancy for Ozema shortly before Ozema converts and then dies, both women are mentioned as having their own personal histories_-but histories which will soon draw to a close. Shortly before Ozema's death, "all but those who were in the secret of Ozema's history withdrew,"65 and even Mercedes, the heroine and namesake of the novel, tells Luis, "Listen to me, Don Luis... my history will not be long." ${ }^{66}$ These women thus highlight the apocryphal nature of the history Cooper intends to expose to the world.

Cooper's interaction with history is one of the most fascinating aspects of Mercedes of Castile, and an understanding of the way he uses the well-known voyage of Columbus to couch his own views on colonization, the spread of Christianity, and other

\footnotetext{
${ }^{64}$ Present edition, pg. 10.

${ }^{65}$ Townsend 513.

${ }^{66}$ Townsend 501.
} 
important issues stands to inform critical understanding of his other historical fiction. ${ }^{67}$ Cooper interweaves historical incidents with his own fiction in this novel in a way that is very different from his usual method. For instance, in The Last of the Mohicans, Cooper uses the French and Indian War and the massacre of Fort William Henry as a backdrop for the adventure of Hawkeye, Chingatchgook, Uncas, Cora, Alice, and Duncan; but he does not create a pretense of writing an actual history. He does in Mercedes, as this last example will demonstrate. When Luis is about to explore Haiti, the narrator explains how Columbus charges Luis to keep his exploration secret so that other sailors won't ask for the same privilege. The succeeding statement is characteristic of the narrative treatment given the fictional portion of the novel:

It is owing to these circumstances, as well as to the general mystery that was thrown about the connection of the young grandee with the expedition, that the occurrences we are about to relate were never entered by the admiral in his journal, and have consequently escaped the prying eyes of the various historians who have subsequently collected so much from that pregnant document. ${ }^{68}$

Cooper deliberately poses as a historian for the very purpose of satirizing the process of historical writing. By telling his own version of Columbus's voyage - the version not found in the admiral's journal, the primary documentary source-Cooper emphasizes how ultimately insufficient are the written histories which are given to the world; not everything makes it into the history, only the events which the author of the history

\footnotetext{
${ }^{67}$ Two of the Leatherstocking Tales were, in fact, written immediately before and after Mercedes: The Pathfinder (1839) and The Deerslayer (1841).

${ }^{68}$ Townsend 379.
} 
wishes to portray. Cooper finds Prescott's and Irving's histories incomplete, and he adds to the Columbus historical corpus incisive criticisms of early colonization, ineffectual and misguided evangelism, and sexual ensnarement of the natives by the colonizers. The sailor Sancho tells Mercedes, "Any one who hath been in a battle, or seen any other great adventure, and then cometh to hear it read of, afterward, will soon learn to understand the difference between the thing itself, and the history that may be given of it." ${ }^{69}$ Mercedes of Castile pretends to approximate "the thing itself" while acknowledging the fact that it, too, is just one history of many.

Covering all the potential points of critical inquiry in Mercedes of Castile is impossible to do within the scope of an introduction. I hope, however, that these brief glimpses into what I consider to be some of the more intriguing problems of the novel will inspire readers and scholars alike to turn their attention to a novel long neglected but nevertheless of great and enduring significance.

\footnotetext{
${ }^{69}$ Townsend 451.
} 
Preface

So much has been written of late years, touching the discovery of America, that it would not be at all surprising should there exist a disposition in a certain class of readers to deny the accuracy of the statements in this work. Some may refer to history, with a view to prove that there never were such persons as our hero and heroine, and fancy that by establishing these facts, they completely destroy the authenticity of the whole book. In answer to this anticipated objection, we will state, that after carefully perusing several of the Spanish writers, from Cervantes to the translator of the journal of Columbus, the

10 Alpha and Omega of peninsular literature, and after having read both Irving and Prescott from beginning to end, we do not find a syllable in either of them, that we understand to be conclusive evidence, or indeed to be any evidence at all, on the portions of our subject that are likely to be disputed. Until some solid affirmative proof, therefore, can be produced against us, we shall hold our case to be made out, and rest our claims to be

15 believed on the authority of our own statements. Nor do we think there is any thing either unreasonable or unusual, in this course, as perhaps the greater portion of that which is, daily and hourly, offered to the credence of the American public, rests on the same species of testimony, with the trifling difference that we state truths, with a profession of fiction, while the great moral caterers of the age state fiction with the profession of truth.

20 If any advantage can be fairly obtained over us, in consequence of this trifling discrepancy, we must fain submit.

There is one point, notwithstanding, concerning which it may be well to be frank, at once. The narrative of the "Voyage to Cathay," has been written with the journal of the Admiral before us; or, rather with all of that journal, that has been given to the world

25 through the agency of a very incompetent and meager editor. ${ }^{\text {i }}$ Nothing is plainer than the general fact that this person did not always understand his author, and in one particular circumstance he has written so obscurely, as not a little to embarrass even a novelist, whose functions naturally include an entire familiarity with the thoughts, emotions, characters, and, occasionally, with the unknown fates of the subjects of his pen. The

30 nautical day formerly commenced at Meridian, and with all our native ingenuity and high professional prerogatives we have not been able to discover whether the editor of the journal has adopted that mode of counting time, or whether he has condescended to use the more vulgar and irrational practice of landsmen. It is our opinion, however, that in the spirit of impartiality which becomes an historian he has adopted both. This little

35 peculiarity might possibly embarrass a superficial critic, but accurate critics being so very common, we feel no concern on this head, well knowing that they will be much more apt to wink at these minor inconsistencies, than to pass over an error of the press, or a comma with a broken tail. As we wish to live on good terms with this useful class of our fellow creatures, we have directed the printers to mis-spell some eight or ten words for their

40 convenience, and to save them from head-aches, have honestly stated this principal difficulty ourselves.

Should the publicity which is now given to the consequences of commencing a day in the middle, have the effect to induce the government to order that it shall, in 
future, with all American seamen, commence at one of its ends, something will be gained in the way of simplicity, and the writing of novels will, in-so-much, be rendered easier and more agreeable.

As respects the minor characters of this work, very little need be said. Every one 5 knows that Columbus had seamen in his vessels, and that he brought some of the natives of the islands he had discovered, back with him to Spain. The reader is now made much more intimately acquainted with certain of these individuals, we will venture to say, than he can be possibly by the perusal of any work previously written. As for the subordinate incidents connected with the more familiar events of the age, it is hoped they will be

10 found so completely to fill up this branch of the subject, as to render future investigations unnecessary. 


\title{
Chapter XXIII
}

\author{
"Thou seemest to Fancy's eye \\ An animated blossom born in air; \\ Which breathes and bourgeons in the golden sky, \\ And sheds its odours there."
}

\section{SUTERMEISTER.}

10 Notwithstanding his native resolution, and an indifference to danger that amounted to recklessness, Luis did not find himself alone with the Haytians, without at least a lively consciousness of the novelty of his situation. Still, nothing occurred to excite uneasiness, and he continued his imperfect communications with his new friends, occasionally throwing in a remark to Sancho in Spanish, who merely wanted

15 encouragement to discourse by the hour. Instead of following the boat of the Santa Maria, on board which the ambassador had embarked, the canoe pushed on several leagues farther east, it being understood that Luis was not to present himself in the town of Guacanagari, ${ }^{\text {ii }}$ until after the arrival of the ships, when he was to rejoin his comrades stealthily, or in a way not to attract attention.

20 Our hero would not have been a true lover, had he remained indifferent to the glories of the natural scenery that lay spread before his eyes, as he thus coasted the shores of Española. The boldness of the landscape, as in the Mediterranean, was relieved by the softness of a low latitude, which throws some such witchery around rocks and promontories, as a sunny smile lends to female beauty. More than once did he burst out

25 into exclamations of delight, and as often did Sancho respond in the same temper, if not exactly in the same language, the latter conceiving it to be a sort of duty to echo all that the young noble said, in the way of poetry.

"I take it, Señor Conde," observed the seaman, when they had reached a spot several leagues beyond that where the launch of the ship had put to shore, "I take it for

30 granted, Señor Conde, that your Excellency knoweth whither these naked gentry are paddling, all this time. They seem in a hurry, and have a port in their minds, if it be not in view."

"Art thou uneasy, friend Sancho, that thou puttest thy question thus earnestly?"

"If I am, Don Luis, it is altogether on account of the family of Bobadilla, which

35 would lose its head, did any mishap befall your excellency. What is it to Sancho, of the Ship Yard Gate, whether he is married to some princess in Cipango, and gets to be adopted by the Great Khan, or whether he is an indifferent mariner out of Moguer? It is very much as if one should offer him the choice between wearing a doublet and eating garlick, and going naked on sweet fruits and a full stomach. I take it, Señor, your

40 excellency would not willingly exchange the castle of Llera for the palace of this Great Cacique?"

"Thou art right, Sancho; even rank must depend on the state of society in which we live. A Castilian noble cannot envy even a Haytian Sovereign." 
"More especially, since my lord, the Señor Don Almirante, hath publickly proclaimed, that our Gracious Lady, the Doña Isabella, is henceforth and for ever to be queen over him," returned Sancho, with a knowing glance of the eye. "Little do these worthy people understand the honor that is in store for them, and least of all His Highness, King Guacanagari!"

"Hush, Sancho, and keep thy unpleasant intimations in thine own breast. Our friends turn the heads of the canoes towards yonder river's mouth, and seem bent on landing."

By this time, indeed, the natives had coasted as far as they intended, and were

10 turning in towards the entrance of a small stream, which, taking its rise among the noble mountains that were grouped inland, found its way through a smiling valley to the ocean. This stream was neither broad nor deep, but it contained far more than water sufficient for any craft used by the natives. Its banks were fringed with bushes, and as they glided up it, Luis saw fifty sites where he thought he could be content to pass his life, provided,

15 always, that it might possess the advantage of Mercedes's presence. It is scarcely necessary to add, too, that in all these scenes he fancied his mistress attired in the velvets and laces that were then so much used by high born dames, and that he saw her in her natural grace, embellished by the courtly ease and polished accessories of one who lived daily, if not hourly, in the presence of her royal mistress.

As the canoe shut in the coast, by entering between the two points that formed the river's mouth, Sancho pointed out to the young noble, a small fleet of canoes that was coming down before the wind from the eastward, apparently bound, like so many more they had seen that day, to the Bay of Acúl, on a visit to the wonderful strangers. The natives in the canoe, also beheld this little flotilla, which was driving before the wind

25 under cotton sails, and by their smiles and signs showed that they gave it the same destination. About this time, too, or just as they entered the mouth of the stream, Mattinao drew from under a light cotton robe that he occasionally wore, a thin circlet of pure gold, which he placed upon his head, in the manner of a coronet. This Luis knew was a token that he was a cacique, one of those who were tributary to Guacanagari, and

30 he rose to salute him at this evidence of his rank, an act that was imitated by all of the Haytians also. From this assumption of state, Luis rightly imagined that Mattinao had now entered within the limits of a territory that acknowledged his rule. From the moment that this young cacique threw aside his incognito, he ceased to paddle, but assuming an air of authority and dignity, he attempted to converse with his guest in the best manner

35 their imperfect means of communication would allow. He often pronounced the word, "Ozema," and Luis inferred from the manner in which he used it, that it was the name of a favorite wife, it having been already ascertained by the Spaniards, or at least it was thought to be ascertained, that the caciques indulged in polygamy, while they rigidly restricted their subjects to one wife.

40 The canoe ascended the river several miles, until it reached one of those tropical vallies in which nature seems to expend her means of rendering this earth inviting. While the scenery had much of the freedom of a wilderness, the presence of man for centuries, had deprived it of all its ruder and more savage features. Like those who tenanted it, the spot possessed the perfection of native grace, unfettered and uninvaded by any of the 
more elaborate devices of human expedients. The dwellings were not without beauty, though simple as the wants of their owners; the flowers bloomed, in mid winter; and the generous branches still groaned with the weight of their nutritious and palatable fruits.

Mattinao was received by his people, with an eager curiosity, blended with

5 profound respect. His mild subjects crowded around Luis and Sancho, with some such wonder, as a civilized man would gaze at one of the prophets, were he to return to earth in the flesh. They had heard of the arrival of the ships, but they did not the less regard their inmates as visitors from heaven. This probably was not the opinion of the more elevated in rank, for, even in the savage state, the vulgar mind is far from being that of

10 the favored few. Whether it was owing to his greater facility of character, and to habits that more easily adapted themselves to the untutored notions of the Indians, or to their sense of propriety, Sancho soon became the favorite with the multitude; leaving the Count of Llera more especially to the care of Mattinao, and the principal men, of his tribe. Owing to this circumstance, the two Spaniards were soon separated, Sancho being

15 led away by the oi polloi, to a sort of square in the centre of the village, leaving Don Luis in the habitation of the Cacique.

No sooner did Mattinao find himself in the company of our hero, and that of two of his confidential chiefs, than the name of "Ozema" was repeated eagerly among the Indians. A rapid conversation followed, a messenger was despatched, Luis knew not

20 whither, and then the chiefs took their departure, leaving the young Castilian alone with the Cacique. Laying aside his golden band, and placing a cotton robe about his person, which had hitherto been nearly naked, Mattinao made a sign for his companion to follow him, and left the building. Throwing the buckler over his shoulder, and adjusting the belt of his sword in a way that the weapon should not incommode him in walking, Luis

25 obeyed with as much confidence as he would have followed a friend along the streets of Seville.

Mattinao led the way through a wilderness of sweets, where tropical plants luxuriated beneath the branches of trees loaded with luscious fruits, holding his course by a foot-path which lay on the banks of a torrent that flowed from a ravine, and poured its

30 waters into the river below. The distance he went might have been half a mile. Here he reached a cluster of rustic dwellings that occupied a lovely terrace on a hill side, whence they overlooked the larger town, below the river, and commanded a view of the distant ocean. Luis saw at a glance that this sweet retreat was devoted to the uses of the gentler sex, and he doubted not that it formed a species of seraglio, set apart for the wives of the

35 young Cacique. He was led into one of the principal dwellings, where the simple but grateful refreshments used by the natives, were again offered to him.

The intercourse of a month had not sufficed to render either party very familiar with the language of the other. A few of the commoner words of the Indians had been caught by the Spaniards, and perhaps Luis was one of the most ready in their use; still, it

40 is highly probable he was oftener wrong than right, even when he felt the most confident of his success. But the language of friendship is not easily mistaken, and our hero had not entertained a feeling of distrust from the time he left the ships, down to the present moment. 
Mattinao had despatched a messenger to an adjacent dwelling when he entered that in which Luis was now entertained, and when sufficient time had been given for the last to refresh himself, the cacique arose, and by a courteous gesture, such as might have become a master of ceremonies in the court of Isabella, he again invited the young

5 grandee to follow. They took their way along the terrace, to a house larger than common, and which evidently contained several subdivisions, as they entered into a sort of anteroom. Here they remained but a minute; the Cacique, after a short parley with a female, removing a curtain ingeniously made of sea weed, and leading the way to an inner apartment. It had but a single occupant, whose character Luis fancied to be

10 announced in the use of the single word "Ozema," that the Cacique uttered in a low affectionate tone, as they entered. Luis bowed to this Indian beauty, as profoundly as he could have made his reverence to a high born damsel of Spain; then, recovering himself, he fastened one long, steady look of admiration on the face of the curious but halffrightened young creature who stood before him, and exclaimed, in such tones as only

15 indicate rapture, admiration and astonishment mingled-

"Mercedes!"

The young Cacique repeated this name, in the best manner he could, evidently mistaking it for a Spanish term to express admiration, or satisfaction; while the trembling young thing, who was the subject of all this wonder, shrunk back a step, blushed,

20 laughed, and muttered in her soft low musical voice, "Mercedes," as the innocent take up, and renew, any source of their harmless pleasures. She then stood, with her arms folded meekly on her bosom, resembling a statue of wonder.

But it may be necessary to explain, why, at a moment so peculiar, the thoughts and tongue of Luis had so suddenly reverted to his mistress. In order to do this, we shall

25 first attempt a short description of the person and appearance of Ozema, as was, in fact, the name of the Indian beauty.

All the accounts agree in describing the Aborigines of the West Indies, as being singularly well formed, and of a natural grace in their movements, that extorted a common admiration among the Spaniards. Their colour was not unpleasant, and the

30 inhabitants of Hayti, in particular, were said to be but very little darker than the people of Spain. Those who were but little exposed to the bright sun of that climate, and who dwelt habitually beneath the shades of groves, or in the retirement of their dwellings, like persons of similar habits in Europe, might by comparison, have even been termed fair. Such was the fact with Ozema, who, instead of being the wife of the young Cacique, was

35 his only sister. According to the laws of Hayti, the authority of a cacique was transmitted through females, and a son of Ozema was looked forward to, as the heir of his uncle. Owing to this fact, and to the circumstances that the true royal line, if a term so dignified can be applied to a state of society so simple, was reduced to these two individuals, Ozema had been more than usually fostered by the tribe, leaving her free from care, and 40 as little exposed to hardships, as at all comported with the condition of her people. She had reached her eighteenth year, without having experienced any of those troubles and exposures which are, more or less, the inevitable companions of savage life; though it was remarked by the Spaniards, that all the Indians they had yet seen, seemed more than usually free from evils of this character. They owed this exemption to the generous 
quality of the soil, the genial warmth of the climate, and the salubrity of the air. In a word, Ozema, in her person, possessed just those advantages that freedom from restraint, native graces, and wild luxuriance might be supposed to lend the female form, under the advantages of a mild climate, a healthful and simple diet, and perfect exemption from exposure, care, or toil. It would not have been difficult to fancy Eve such a creature, when she first appeared to Adam, fresh from the hands of her divine creator, modest, artless, timid and perfect.

The Haytians used a scanty dress, though it shocked none of their opinions to go forth in the garb of nature. Still, few of rank were seen without some pretensions to attire,

10 which was worn rather as an ornament, or a mark of distinction, than as necessary either to usage or to comfort. Ozema, herself, formed no exception to the general rule. A cincture of Indian cloth, woven in gay colours, circled her slender waist, and fell nearly as low as her knees; a robe of spotless cotton, inartificially made, but white as the driven snow, and of a texture so fine that it might have shamed many of the manufactures of our

15 own days, fell like a scarf across a shoulder, and was loosely united at the opposite side, dropping in folds nearly to the ground. Sandals of great ingenuity and beauty, protected the soles of feet that a queen might have envied, and a large plate of pure gold, rudely wrought, was suspended from her neck by a string of small, but gorgeous shells.

Bracelets of the latter were on her pretty wrists, and two light bands of gold encircled

20 ancles that were as faultless as those of the Venus of Naples. In that region, the fineness of the hair was thought the test of birth, with better reason than many imagine the feet and hands to be, in civilized life. As power and rank had passed from female to female, in her family, for several centuries, the hair of Ozema was silken, soft, waving, exuberant, and black as jet. It covered her shoulders, like a glorious mantle, and fell as low as her

25 simple cincture. So light and silken was this natural veil, that its ends waved in the gentle current of air that was rather breathing than blowing through the apartment.

Although this extraordinary creature was much the loveliest specimen of young womanhood that Luis had seen among the wild beauties of the islands, it was not so much her graceful and well rounded form, or even the charms of face and expression, that

30 surprised him, as a decided and accidental resemblance to the being he had left in Spain, and who had so long been the idol of his heart. This resemblance alone, had caused him to utter the name of his mistress, in the manner related. Could the two have been placed together, it would have been easy to detect marked points of difference between them, without being reduced to comparing the intellectual and thoughtful expression of our 35 heroine's countenance, with the wondering, doubting, half-startled look of Ozema; but, still the general likeness was so strong that no person who was familiar with the face of one, could fail to note it on meeting with the other. Side by side, it would have been discovered that the face of Mercedes had the advantage in finesse and delicacy; that her features and brow were nobler; her eye more illuminated by the intelligence within; her

40 smile more radiant with thought and the feelings of a cultivated woman; her blush more sensitive, betraying most of the consciousness of conventional habits; and that the expression generally was much more highly cultivated, than that which sprung from the artless impulses and limited ideas of the young Haytian. Nonetheless, in mere beauty, in youth, and tint, and outline, the disparity was scarcely perceptible, while the resemblance 
was striking, and on the score of animation, native frankness, ingenuousness, and all that witchery which ardent and undisguised feeling lends to woman, many might have preferred the confiding abandon of the beautiful young Indian to the more trained and dignified reserve of the Castilian heiress. What, in the latter was earnest, high-souled, native, but religious enthusiasm, in the other was merely the out-pourings of unguided impulses, which, however feminine in their origin, were but little regulated in their indulgence.

"Mercedes!" exclaimed our hero, when this vision of Indian loveliness unexpectedly broke on his sight. "Mercedes_-" repeated Mattinao; "Mercedes!"

10 murmured Ozema, recoiling a step, blushing, laughing, and then resuming her innocent confidence, as she several times uttered the same word, which she also mistook for an expression of admiration, in her own low, melodious voice.

Conversation being out of the question, there remained nothing for the parties but to express their feelings by signs and acts of amity. Luis had not come on his little

15 expedition unprovided with presents. Anticipating an interview with the wife of the cacique, he had brought up from the village below, several articles that he supposed might suit her untutored fancy. But the moment he beheld the vision that actually stood before him, they all seemed unworthy of such a being. In one of his onsets against the Moors, he had brought off a turban of rich but light cloth, and he had kept it as a trophy, 20 occasionally wearing it, in his visits to the shore, out of pure caprice, and as a sort of ornament that might well impose on the simple-minded natives. These vagaries excited no remarks, as mariners are apt to indulge their whims, in this manner, when far from the observations of those to whom they habitually defer. This turban was on his head, at the moment he entered the apartment of Ozema, and overcome with the delight of finding so

25 unexpected a resemblance, and, possibly, excited by so unlooked-for an exhibition of feminine loveliness, he gallantly unrolled it, threw out the folds of rich cloth, and cast it over the shoulders of the beautiful Ozema, as a mantle.

The expressions of gratitude and delight that escaped this unsophisticated young creature, were warm, sincere, and undisguised. She cast the ample robe on the ground

30 before her, repeated the word "Mercedes," again and again, and manifested her pleasure with all the warmth of a generous and ingenuous nature. If we were to say that this display of Ozema was altogether free from the child-like rapture that was perhaps unseparable from her ignorance, it would be attributing to her benighted condition the experience and regulated feelings of an advanced civilization; but, notwithstanding the

35 guileless simplicity with which she betrayed her emotions, her delight was not without much of the dignity and tone that usually mark the conduct of the superior classes all over the world. Luis fancied it as graceful as it was naive and charming. He endeavored to imagine the manner in which the Lady of Valverde might receive an offering of precious stones from the gracious hands of Doña Isabella, and he even thought it very possible that 40 the artless grace of Ozema was not far behind, what he knew would be the meek selfrespect, mingled with grateful pleasure, that Mercedes could not fail to exhibit.

While thoughts like these were passing through his mind, the Indian girl laid aside her own less enticing robe, without a thought of shame, and then she folded her faultless form in the cloth of the turban. This act was no sooner done, with a grace and freedom 
peculiar to her unfettered mind, than she drew the necklace of shells from her person, and advancing a step or two, towards our hero, extended the offering with a half averted face, though the laughing and willing eyes more than supplied the place of language. Luis accepted the gift, with suitable eagerness, nor did he refrain from using the Castilian gallantry of kissing the pretty hand from which he took the bawbles.

The Cacique, who had been a pleased spectator of all that passed, now signed for the Count to follow him, leading the way towards another dwelling. Here Don Luis was introduced to other young females, and to two or three children, the former of whom, he soon discovered, were the wives of Mattinao, and the latter his offspring. By dint of

10 gestures, a few words, and such other means of explanation as were resorted to between the Spaniards and the natives, he now succeeded in ascertaining the real affinity which existed between the cacique and Ozema. Our hero felt a sensation like pleasure when he discovered that the Indian beauty was not married, and he was fain to refer the feelingperhaps justly — to a sort of jealous sensitiveness that grew out of her resemblance to

15 Mercedes.

The remainder of that, and the whole of the three following days, were passed by Luis, with his friend the cacique, in this, the favorite and sacred residence of the latter. Of course our hero was, if any thing, a subject of greater interest to all his hosts, than they could possibly be to him. They took a thousand innocent liberties with his person;

20 examining his dress and the ornaments he wore, not failing to compare the whiteness of his skin with the redder tint of that of Mattinao. On all these occasions Ozema was the most reserved and shy, though her look followed every movement, and her pleased countenance denoted the interest she felt in all that concerned the stranger. Hours at a time, did Luis lie stretched on fragrant mats near this artless and lovely creature, studying

25 the wayward expression of her features, in the fond hope of seeing stronger and stronger resemblances to Mercedes, and sometimes losing himself in that which was peculiarly her own. In the course of the time passed, in these dwellings, efforts were made by the count to obtain some useful information of the island, and whether it was owing to her superior rank, or to a native superiority of mind, or to a charm of manner, he soon fancied

30 that the Cacique's beautiful sister succeeded better in making him understand her meaning, than either of the wives of Mattinao, or the Cacique himself. To Ozema, then, Luis put most of his questions, and ere the day had passed, this quick-witted and attentive girl had made greater progress in opening an intelligible understanding between the adventurers and her country-men, than had been accomplished by the communications of

35 the two previous months. She caught the Spanish words with a readiness that seemed instinctive, pronouncing them with an accent that only rendered them prettier and softer to the ear.

Luis de Bobadilla was just as good a catholic as a rigid education, a wandering life, and the habits of the camp would be apt to make one of his rank, years and

40 temperament. Still, that was an age, in which most laymen had a deep reverence for religion, whether they actually submitted to its purifying influence, or not. If there were any free-thinkers, at all, they existed principally among those who passed their lives in their closets, or were to be found among the churchmen, themselves; who often used the cowl as a hood to conceal their infidelity. His close association with Columbus, too, had 
contributed to strengthen our hero's tendency to believe in the constant supervision of Providence, and he now felt a strong inclination to fancy that this extraordinary facility of Ozema's in acquiring languages, was one of its semi-miraculous provisions, made with a view to further the introduction of the religion of the cross among her people. Often did

5 he flatter himself, as he sat gazing into the sparkling, and yet mild, eyes of the girl, listening to her earnest efforts to make him comprehend her meaning, that he was to be the instrument of bringing about this great good, through so young and charming an agent. The admiral had also enjoined on him, the importance of ascertaining, if possible, the position of the mines, and he had actually succeeded in making Ozema comprehend

10 his questions on a subject that was all engrossing with most of the Spaniards. Her answers were less intelligible, but Luis thought they never could be sufficiently full; flattering himself, the whole time, that he was only laboring to comply with the wishes of Columbus.

The day after his arrival, our hero was treated to an exhibition of some of the

15 Indian games. These sports have been too often described to need repetition here, but, in all their movements and exercises, which were altogether pacific, the young princess was conspicuous for grace and skill. Luis, too, was required to show his powers, and being exceedingly athletic and active, he easily bore away the palm from his friend Mattinao. The young cacique manifested neither jealousy, nor disappointment, at this result, while

20 his sister laughed and clapped her hands with delight, when he was outdone, even at his own sports, by the greater strength, or greater efforts of his guest. More than once, the wives of Mattinao seemed to utter gentle reproaches at this exuberance of feeling, but Ozema answered with smiling taunts, and Luis thought her, at such moments, more beautiful than even imagination could draw, and perhaps with justice; for her cheeks were

25 flushed, her eyes became as brilliant as ornaments of jet, and the teeth that were visible between lips like cherries, resembled rows of ivory. We have said that the eyes of Ozema were black, differing in this particular, from the deep-blue melancholy orbs of the enthusiastic Mercedes, but still they were alike, so often uttering the same feelings, more especially touching matters in which Luis was concerned. More than once, during the

30 trial of strength, did the young man fancy that the expression of the rapture which fairly danced in the eyes of Ozema, was the very counterpart of that of deep-seated delight which had so often beamed on him, from the glances of Mercedes in the tourney; and, at such times, it struck him that the resemblance between the two was so strong, as - after some allowance had been made for dress and other sufficiently striking circumstances35 almost to render them identical.

The reader is not to suppose from this, that our hero was actually inconstant to his ancient love. Far from it. Mercedes was too deeply enshrined in his heart—and Luis, with all his faults, was as warm-hearted and true-hearted a cavalier as breathed-to be so easily dispossessed. But he was young, distant from her he had so long adored, and was,

40 withall, not altogether insensible to admiration so artlessly and winningly betrayed by the Indian-girl. Had there been the least immodest glance, any proof that art or design lay at the bottom of Ozema's conduct, he would at once have taken the alarm, and been completely disenthralled from his temporary delusion; but, on the contrary, all was so frank and natural with this artless girl; when she most betrayed the hold he had taken of 
her imagination, it was done with a simplicity so obvious, a naiveté so irrepressible, and an ingenuousness so clearly the fruits of innocence, that it was impossible to suspect artifice. In a word, our hero merely showed that he was human, by yielding in a certain degree to a fascination that, under the circumstances, might well have made far deeper inroads on the faith of even men who enjoyed much better reputations for stability of purpose.

In situations of so much novelty, time flies swiftly, and Luis himself was astonished when, on looking back, he remembered that he had now been several days with Mattinao, most of which period, had actually been passed in what might not inaptly

10 have been termed the seraglio of the Cacique. Sancho of the Ship Yard Gate had not been, in the least, neglected all this time. He had been a hero, in his own circle, as well as the young noble, nor had he been at all forgetful of his duty on the subject of searching for gold. Though he had neither acquired a single word of the Haytian language, nor taught a syllable of Spanish to even one of the laughing nymphs who surrounded him, he

15 had decorated the persons of many of them with hawk's-bells, and had contrived to abstract from them, in return, every ornament that resembled the precious metal, which they possessed. This transfer no doubt was honestly effected, however, having been made on that favorite principle of the Free Trade Theorists, which maintains that trade is merely an exchange of equivalents; overlooking all the adverse circumstances which may

20 happen, just at the moment, to determine the standard of value. Sancho had his notions of commerce as well as the modern philosophers, and, as he and Luis occasionally met during their sojourn with Mattinao, he revealed a few of his opinions on this interesting subject, in one of their interviews.

"I perceive thou hast not forgotten thy passion for doblas, friend Sancho," said

25 Luis, laughing, as the old seaman exhibited the store of dust and golden plates he had collected; "there is sufficient of the metal in thy sack to coin a score of them, each having the royal countenances of our Lord the King, and our Lady the Queen!"

"Double that, Señor Conde; just double that, and all for the price of some seventeen hawk's-bells, that cost but a handful of maravedis. By the Mass! this is a most

30 just and holy trade, and such as it becomes us Christians to carry on. Here are these savages, they think no more of gold, than your Excellency thinks of a dead Moor, and to be revenged on them, I hold a hawk's-bell just as cheap. Let them think as poorly as they please of their ornaments and yellow dust, they will find me just as willing to part with the twenty hawk's-bells that remain. Let them barter away, they will find me as ready as 35 they possibly can be, to give nothing for nothing."

"Is this quite honest, Sancho, to rob an Indian of his gold, in exchange for a bawble that copper so easily purchaseth? Remember thou art a Castilian, and henceforth give two hawk's-bells, where thou hast hitherto given but one."

"I never forget my birth, Señor, for happily the Ship Yard of Moguer is in old 40 Spain. Is not the value of a thing to be settled by what it will bring in the market? Ask any of our traders, and they will tell you this, which is clear as the sun in the heavens. When the Venitians lay before Candia, grapes and figs and Greek wine could be had for the asking in that island, while western articles commanded any price. Oh! nothing is 
plainer than the fact that every thing hath its price, and it is real trade to give one worthless commodity for another."

"If it be honest to profit by the ignorance of another," answered Luis, who had a nobleman's contempt for Commerce, "then is it just to deceive the child and the idiot."

"God forbid, and especially St. Andrew my patron, that I should do any thing so wicked. Hawk's-bells are of more account than gold, in Hayti, Señor, and happening to know it, I am willing to part with the precious things for the dross. You see, I am generous instead of being avaricious, for all parties are in Hayti, where the value of the articles must be settled. It is true, that after running great risks at sea, and undergoing

10 great pains and chances by carrying this gold to Spain, I may be requited for my trouble, and get enough benefit to make an honest livelihood. I hope Doña Isabella will have so much feeling for these, her new subjects, as to prevent their ever going into the shipping business, a most laborious and dangerous calling, as we both well know."

"And why art thou so particular in desiring this favor in behalf of these poor

15 islanders, and that too, Sancho, at the expense of thine own bones?"

"Simply, Señor," answered the knave with a cunning leer, "lest it unsettle Trade, which ought to be as free and unencumbered as possible. Here, now, if we Spaniards come to Hayti, we sell one hawk's-bell for a dobla in gold; whereas, were we to give these savages the trouble to come to Spain, a dobla of their gold would buy a hundred

20 hawk's-bells ! No - no - it is right as it is, and may a double allowance of purgatory be the lot of him, who wishes to throw any difficulties in the way of a good, honest, free and civilizing trade, say I."

Sancho was thus occupied in explaining his notions of Free Trade, the great mystification of modern philanthropists, when there arose such a cry in the village of

25 Mattinao, as is only heard in moments of extreme jeopardy and sudden terror. The conversation took place in the grove, about midway between the town and the private dwellings of the cacique, and so implicit had become the confidence the two Spaniards reposed in their friends, that neither had any other arms about his person, than those furnished by nature. Luis had left both sword and buckler, half an hour earlier, at the feet

30 of Ozema, who had been enacting a mimic hero, with his weapons, for their mutual diversion; while Sancho had found the arquebuse much too heavy to be carried about for a play thing. The last was deposited in the room where he had taken up his comfortable quarters.

"Can this mean treachery, Señor?" exclaimed Sancho. "Have these blackguards

35 found out the true value of hawk's-bells, after all, and do they mean to demand the balance due them?"

"My life on it, Mattinao and all his people are true, Sancho. This uproar hath a different meaning - hark! is not that the cry of 'Caonabo'?"

"The very same, Señor! That is the name of the Carib cacique, who is the terror of 40 all these tribes." iii

"Thy arquebuse, Sancho, if possible; then join me at the dwellings above. Ozema and the wives of our good friend must be defended, at every hazard!"

Luis had no sooner given these orders, than he and Sancho separated, the latter running towards the town, which by this time was a scene of wild tumult, while our hero 
slowly and sullenly retired towards the private dwellings of the cacique, occasionally looking back, as if he longed to plunge into the thickest of the fray. Twenty times did he wish for his favorite charger and a stout lance, when, indeed, it would not have been an extraordinary feat for a knight of his prowess to put to flight a thousand enemies like those who now menaced him. Often had he singly broken whole ranks of Christian foot soldiers, and it is well known that solitary individuals when mounted, subsequently drove hundreds of the natives before them.

The alarm had reached the dwellings of Mattinao, before our hero. When he entered the house of Ozema, he found its mistress surrounded by fifty females, some of

10 whom had already ascended from the town below, each of whom was eagerly uttering the terrible name of "Caonabo." Ozema herself, was the most collected of them all, though it was apparent that, from some cause, she was an object of particular solicitude with those around her. As Luis entered the apartment, the wives of Mattinao were pressing around the princess, and he soon gathered from their words and entreaties, that they urged her to

15 fly, lest she should fall into the hands of the Carib chief. He even fancied, and he fancied it justly, that the rest of the females supposed the seizure of the cacique's beautiful sister to be the real object of the sudden attack. This conjecture, in no manner lessened Luis' ardor in the defence. The moment Ozema caught sight of him, she flew to his side, clasping her hands, and uttering the name of "Caonabo," in a tone that would have melted 20 a heart of stone. At the same time, her eyes spoke a language of hope, confidence and petition that was not necessary to enlist all our hero's resolution on her side. In a moment the sword of the young cavalier was in his hand, and the buckler on his arm. He then assured the princess of his zeal, in the best manner he could, by placing the buckler before her throbbing breast, and waving the sword, as in defiance of her enemies: no 25 sooner was this pledge given, than every other female disappeared, some flying to the rescue of their children, and all endeavoring to find places of concealment. By this singular and unexpected desertion, Luis found himself, for the first time since they had met, alone with Ozema.

To remain in the house would be to suffer the enemy to approach unseen, and the

30 shrieks and cries sufficiently announced that, each moment, the danger drew nearer. Luis, accordingly, made a sign for the girl to follow him, first rolling the turban into a bundle and placing it on her arm, that it might serve her, at need, as a species of shield against the hostile arrows. While he was thus employed, Ozema's head fell upon his breast, and the excited girl burst into tears. This display of weakness, however, lasted but a moment, 35 when she aroused herself, smiled through her tears, pressed the arm of Luis convulsively, and became the Indian heroine, again. They then left the building together.

Luis soon perceived that his retreat from the house had not been made a moment too soon. The family of Mattinao had already disappeared, and a strong party of the invaders was in full view, rushing madly up the grove, silent, but evidently bent on 40 seizing their prey. He felt Ozema, who clung to his arm, tremble violently, and then he heard her murmuring-

"Caonabo-no-no-no."

The young Indian princess had caught the Spanish monosyllable of dissent, and Luis understood this exclamation to express her strong disinclination to become a wife of 
the Carib chief. His resolution to protect her, or to die, was in no manner lessened by this involuntary betrayal of feelings, which he could not but think might have some connection with himself; for, while our hero was both honorable and generous, he was human, and consequently well disposed to take a favorable view of his own powers of pleasing. It was only in connection with Mercedes, that Luis de Bobadilla was humble.

A soldier almost from childhood, the young count looked hastily around him for a position that would favor his means of defence, and which would render his arms the most available. Luckily one offered so near him, that it required but a minute to occupy it. The terrace lay against a precipice of rocks, and, a hundred feet from the house, was a

10 spot where the face of this precipice was angular, throwing forward a wall on each side to some distance, while the cliff above overhung the base sufficiently to remove all danger from falling stones. In the angle were several large fragments of rock that would afford shelter against arrows, and, there being a sufficient space of green sward before them, on which a knight might well display his prowess when in possession of this position, our

15 hero felt himself strong, if not impregnable, since he could be assailed only in front. Ozema was stationed behind one of the fragments of the fallen rocks, her person only half concealed, however, concern for Luis, and curiosity as related to her enemies, equally inducing her to expose her head and beautiful bust.

Luis was scarcely in possession of this post, ere a dozen Indians were drawn up in 20 a line, at the distance of fifty yards in his front. They were armed with bows, war-clubs and spears. Being without other defensive armour than his buckler, the young man would have thought his situation sufficiently critical, did he not know that the archery of the natives was any thing but formidable. Their arrows would kill certainly, when shot at short distances, and against the naked skin, but it might be questioned if they would

25 penetrate the stout velvet in which Luis was encased, and fifty yards was not near enough to excite undue alarm. The young man did not dare to retreat to the rocks, as a clear space was indispensable for the free use of his good sword, and to that weapon alone he looked for his eventual triumph.

It was perhaps fortunate for our hero that Caonabo, himself, was not with the

30 party which beleaguered him. That redoubtable chieftain, who had been led to a distance in pursuit of the flying females, under a belief that she he sought was among them, would doubtless have brought the matter to an immediate issue by a desperate charge, when numbers might have prevailed against courage and skill. The actual assailants chose a different course, and began to poise their bows. One of the most skilful among them drew

35 an arrow to the head, and let it fly. The missile glanced from the buckler of the knight, and struck the hill behind him, as lightly as if the parties had been at their idle sports. Another followed, and Luis turned it aside with his sword, disdaining to raise his shield against such a trifle. This cool manner of receiving their assaults caused the Indians to raise a shout; whether in admiration or rage, Luis could not tell.

40 The next attack was more judicious, being made on a principle that Napoleon is said to have adopted in directing discharges of his artillery. All those who had bows, some six or eight, drew their arrows together, and the weapons came rattling on the buckler of the assailed in a single flight. It was not easy to escape altogether from such a combined assault, and our hero received one or two bruises from glancing arrows, though 
no blood followed the blows. A second attempt of the same nature was about to be made, when the alarmed girl rushed from her place of concealment, and, like the Pocahontas of our own history, threw herself before Luis, with her arms meekly placed on her bosom. As soon as she appeared there was a cry of "Ozema"-_"Ozema" among the assailants, who were not Caribs, as all will understand who are familiar with the island history, but milder Haytians, governed by a Carib chief.

In vain Luis endeavored to persuade the devoted girl to withdraw. She thought his life in danger, and no language, had he been able to exert his eloquence on the occasion, could have induced her to leave him exposed to such a danger. As the Indians were

10 endeavoring to obtain chances at the person of Luis without killing the princess, he saw there remained no alternative but a retreat behind the fragments of rock. Just as he obtained this temporary security, a fierce looking warrior joined the assailants, who immediately commenced a vociferous explanation of the actual state of the attack.

"Caonabo?"- demanded Luis of Ozema, pointing towards the new comer.

15 The girl shook her head, after taking an anxious look at the stranger's face, at the same time clinging to our hero's arm, with seductive dependance.

"No- no-no- - she said eagerly. "No Caonabo-Caonabo-no-no-no."

Luis understood the first part of this answer to mean that the stranger was not the Carib chief; and the last to signify Ozema's strong and settled aversion to becoming his wife.

The consultation among the assailants was soon ended. Six of them then poised their war clubs and spears and made a rush for the citadel of the besieged. When they were within twenty feet of his cover, our hero sprang lightly forward on the sward to meet his foes. Two of the spears he received on his buckler, severing both shafts with a

25 single blow of his keen and highly tempered sword. As he recovered from the effort, with an upward cut he met the raised arm of the club-man most in advance. Hand and club fell at his feet with the skilful touch. Making a sweep with the weapon in his front, its point seamed the breasts of the two astonished spearsmen, whose distance alone saved them from more serious injuries.

30 This rapid and unlooked-for execution struck the assailants with awe and dread. Never before had they witnessed the power of metal as used in war; and the sudden amputation of the arm struck them as something miraculous. Even the ferocious Carib fell back in dismay, and Luis felt hopes of victory. This was the first occasion on which the Spaniards had come to blows with the mild inhabitants of the islands they had

35 discovered, though it is usual with the historians to refer to an incident of still later occurrence ${ }^{\text {iv }}$ as the commencement of strife, the severe privacy which has ever been thrown over the connection of Don Luis with the expedition, having completely baffled their slight and superficial researches. Of course the efficiency of a weapon like that used by our hero, was as novel to the Haytians as it was terrific.

40 At this instant a shout among the assailants, and the appearance of a fresh body of the invaders, with a tall and commanding chief at their head, announced the arrival of Caonabo in person. This warlike cacique was soon made acquainted with the state of affairs, and it was evident that the prowess of our hero struck him as much with admiration as with wonder. After a few minutes he directed his followers, to fall back to a 
greater distance, and laying aside his club, he advanced fearlessly towards Luis, making signs of amity.

When the two adversaries met, it was with mutual respect and confidence. The Carib made a short and vehement speech, in which the only word that was intelligible to our hero, was the name of the beautiful young Indian. By this time Ozema had also advanced, as if eager to speak, and her rude suitor turned to her, with an appeal that was passionate, if not eloquent. He laid his hand frequently on his heart, and his voice became soft and persuasive. Ozema replied earnestly, and in the quick manner of one whose resolution was settled. At the close of her speech, the colour mounted to the temples of

10 the ardent girl, and, as if purposely to make her meaning understood by our hero, she ended by saying in Spanish,

"Caonabo-no-no-no!-Luis-Luis!"

The aspect of the hurricane of the tropics is not darker, or more menacing, than the scowl with which the Carib chief heard this unequivocal rejection of his suit,

15 accompanied, as it was, by so plain a demonstration in favor of the stranger. Waving his hand in defiance, he strided back to his people, and issued his orders for a fresh assault.

This time, a tempest of arrows preceded the rush, and Luis was fain to seek his former cover behind the rocks. Indeed, this was the only manner in which he could save the life of Ozema; the devoted girl resolutely persevering in standing before his body, in

20 the hope it would shield him from his enemies. There had been some words of reproach from Caonabo to the Carib chief, who had retreated from the first attack, and the air was yet filled with arrows, as this man rushed forward singly, to redeem his name. Luis met him, firm as the rock behind him. The shock was violent, and the blow that fell on the buckler would have crushed an arm less enured to such rude encounters, but it glanced

25 obliquely from the shield, and the club struck the earth with the weight of a beetle. Our hero saw that all now depended on a deep impression. His sword flashed in the bright sun, and the head of the Carib tumbled by the side of his club, actually leaving the body erect for an instant, so keen was the weapon, and so dexterous had been the blow.

Twenty savages were on the spring, but they stopped like men transfixed, at this 30 unexpected sight. Caonabo, however, undaunted even when most surprised, roared out his orders like a maddened bull, and the wavering crowd was again about to advance, when the lowd report of an arquebuse was heard, followed by the whistling of its deadly missive. A second Haytian fell dead in his tracks. It exceeded the powers of savage endurance to resist this assault, which to their uninstructed minds appeared to come from

35 heaven. In two minutes, neither Caonabo nor any of his followers were visible. As they rushed down the hill, Sancho appeared from a cover, carrying the arquebuse, which he had taken the precaution to reload.

The circumstances did not admit of delay. Not a being of Mattinao's tribe was to be seen in any direction, and Luis made no doubt they had all fled. Determined to save 40 Ozema, at every hazard, he now took his way to the river, in order to escape in one of the canoes. In passing through the town, it was seen that not a house had been plundered, and the circumstance was commented on by the Spaniards, Luis pointing it out to his companion. 
"Caonabo-no-no-no-Ozema!-Ozema!"- - was the answer of the girl, who well knew the real object of the inroad.

A dozen canoes lay at the landing, and five minutes sufficed for the fugitives to enter one, and to commence their retreat. The current flowed towards the sea, and in a 5 couple of hours they were on the ocean. As the wind blew constantly from the eastward, Sancho soon rigged an apology for a sail, and an hour before the sun set, the party landed on a point, that concealed them from the bay; Luis being mindful of the admiral's injunction, to conceal his excursion, lest others might claim a similar favor. 


\section{Explanatory Notes}

${ }^{\mathrm{i}}$ Washington Irving's A History of the Life and Voyages of Christopher Columbus was published in 1828. Irving's work is a romantic history, meaning that he narrates only the facts according to his research but adds his own commentary and analysis, frequently commenting on Columbus's heroic nature while also acknowledging his lack of scientific knowledge relating to his discoveries. Irving set out originally to translate Columbus's journal, but he ended up writing his own history instead.

${ }^{\text {ii }}$ Guacanagari was a historical cacique of the Marién province of Hispaniola, and the first cacique to greet Columbus. His people were Taínos. Samuel M. Wilson, The Indigenous Peoples of the Caribbean (Gainesville: University Press of Florida, 1997) 164, 172.

iii Caonabo, also a historical figure, was the cacique of the neighboring province of Maguana, and one of the Carib people_rivals of the Taínos. Wilson 116.

${ }^{\text {iv }}$ Irving recounted a small fight which took place on the northeastern coast of Hispaniola between Columbus's crew and the Cigüayos. The following is an excerpt from Irving's account: "Having regaled the warrior, and made him various presents, the admiral sent him on shore, in hopes, through his mediation, of opening a trade for gold with his companions. As the boat approached the land, upward of fifty savages, armed with bows and arrows, war-clubs, and javelins, were seen lurking among the trees. On a word from the Indian who was in the boat, they laid by their arms and came forth to meet the Spaniards. The latter, according to directions from the admiral, endeavored to purchase several of their weapons, to take as curiosities to Spain. They parted with two of their bows; but, suddenly conceiving some distrust, or thinking to overpower this handful of strangers, they rushed to the place where they had left their weapons, snatched them up, and returned with cords, as if to bind the Spaniards. The latter immediately attacked them, wounded two, put the rest to flight, and would have pursued them, but were restrained by the pilot who commanded the boat. This was the first contest with the Indians, and the first time that native blood was shed by the white men in the new world." According to Irving, Columbus "gave the name of Golfo de last Flechas, or the Gulf of Arrows" to this bay, "which is now known by the name of the Gulf of Samana" (Irving, Life and Voyages of Christopher Columbus [Chicago: Belford, 1880] 163-64, 165). 


\section{Textual History}

\section{The Present Edition}

This edition of Mercedes of Castile is an eclectic text built up from witnesses whose preparation Cooper had control over. These include the holograph manuscript in Cooper's hand (MS) and the Lea \& Blanchard first American edition (A1), for which Cooper corrected proofs. Following the example of the Cooper Edition, I have adopted the MS reading in cases where its text was likely corrupted during typesetting, and the A1 reading in cases where the change was likely to have been the result of author revision in the proof stage. I have chosen to edit without a copy-text. The idea of a copy-text suggests one witness to be more authoritative than another, and in this case I judge the MS and A1 to be of equal authority. Furthermore, as G. Thomas Tanselle points out in his article "Editing without a Copy-text," the purpose of a copy-text is to have a witness that may provide a default reading, so to speak, when the editor otherwise does not know how to select a reading. ${ }^{70}$ For every variant in my edition, I have been able to use my judgment to select what I deem to be the reading intended by Cooper; therefore, I have had no need of a witness whose readings I must default to.

As a result of editing without a copy-text, my apparatus has necessarily been adapted from the standard form, which includes a list of emendations to the copy-text and a historical collation. The Cooper Edition volumes also include a "Rejected Readings" list, which specifies the readings in their copy-text, the MS, they did not adopt.

\footnotetext{
${ }^{70}$ G. Thomas Tanselle, "Editing without a Copy-Text," in Literature and Artifacts (Charlottesville: Bibliographical Society of the University of Virginia, 1998) 244.
} 
Following Tanselle's recommendation for the apparatus in the absence of a copy-text, ${ }^{71} \mathrm{I}$ have included only a historical collation, which lists the variants in all witnesses, substantive and accidental, designating the variant I have adopted by placing it before the bracket (]).

Although this edition is built primarily from MS and A1 readings, in its preparation I collated all editions from within ten years after Cooper's death (1851), in order to take into account the possibility that he may have left instructions for revisions in subsequent editions. (As far as the extant witnesses and correspondence show, Cooper never revised Mercedes, nor did he intend to do so.) These included the Lea \& Blanchard 1840 (A1), the first British edition by Bentley in London in 1841 (B1), the first French English-language editions by Galignani and Baudry (F1), American reprints by Stringer \& Townsend in 1852 and 1856, and finally the 1859 Townsend edition of Cooper's Works.

II. Note on the Manuscript

Cooper's final-draft holograph manuscript (MS) is a part of the Clifton Waller Barrett Library of American Literature, housed in the Albert and Shirley Small Special Collections Library, at the University of Virginia. The MS is complete with the exception of about two chapters containing part of Columbus' westward ocean voyage. The MS is a set of folio sheets of lined paper, hardbound in blue leather. Cooper wrote in pen on the rectos of the leaves, in a very small, tight hand, which is legible but does create difficulty in distinguishing vowels and capitalization. Cooper left very little space

\footnotetext{
${ }^{71}$ Tanselle 253.
} 
unused on his MS, often running his words right to the edge of the paper. He often writes the epigraph, or "motto," as he calls it, on the verso of the sheet.

Cooper's revisions to the MS are best understood in two categories: draft-stage revisions and later revisions. While writing this draft, Cooper frequently made changes, sometimes striking out words immediately and writing new ones to the right of the deletion, and at other times coming back a moment later, striking through something, and then superlineating the new reading. Cooper also revised his MS after he had finished it, and these later revisions can be distinguished by the fact that they are generally darker and finer than the original ink, which appears to have higher water content, and is consequently of a lighter color. At certain points in the MS, the paper appears to have been damp during Cooper's drafting, as the original ink diffuses around the lines; yet the revisions themselves are sharp. Consequently, I was able to very easily tell which revisions were from drafting, and which were from Cooper's final editing. This MS thus represents two distinct stages of authorship, and is therefore excellent documentation of Cooper's writing and revision habits.

\section{First American Edition}

The Lea \& Blanchard 1840 first American edition (A1) was set from Cooper's revised MS. Many variants in the A1 result from compositors misreading Cooper's hand. For instance, when, upon seeing Ozema, Luis's thoughts suddenly "reverted" to Mercedes in the MS, in A1, they "resorted" to her-the compositor having misread Cooper's "ve" as "so." In another instance, Mattinao enters a realm where his "rule" is recognized in the 
MS, but it is his "will" that is recognized in A1. In such cases, through close examination of the MS, I have been able to restore the proper readings to the text.

Other errors result from compositors mis-setting as a result of Cooper's method of revision. For instance, in the Preface, Cooper superlineates the word fain before submit, in the following: "If any advantage can be fairly obtained over us, in consequence of this trifling discrepancy, we must fain submit." Although it is possible that Cooper added fain during revision of the MS and then decided to cancel it while editing proofs, I think it more likely that the compositor missed it - the addition not being part of the line of text itself. On another occasion, Cooper canceled part of his sentence but neglected to cancel a comma, which due to his changes on the whole, was no longer necessary in the sentence. The compositor retained the comma. In the comparison below, angle brackets $(<>)$ denote a deletion, and the up-and-down arrows $(\uparrow \downarrow)$ denote a superlineated addition. Bolded text indicates a change made during Cooper's later editing, not drafting.

MS: About this time, too, or just as they entered the mouth of the stream, <the principal [illeg.] of the Indians $>, \uparrow$ Mattinao, $\downarrow \uparrow<$ or Mattinao $>\downarrow$ drew from under a light cotton robe

A1: About this time, too, or just as they entered the mouth of the stream, Mattinao, drew from under a light cotton robe 
What I suspect happened here is that Cooper added the bolded "Mattinao," before deleting "the principal [illeg.] of the Indians." If he had not deleted that portion, the comma after "Mattinao" would have made sense. I think it highly likely that Cooper would have deleted the comma, but he did not notice it because it was tucked into another addition.

In all cases, I have emended faulty compositor readings according to the MS. However, in many cases of variation between the MS and A1, it was not compositor misreading but house styling that lay at the root of the change. Trademarks of Lea \& Blanchard house styling include their use of British spellings, such as connexion, ardour, endeavour, and meagre (see the complete list on page 40) and more consistent lowercasing of titles, such as lord, lady, cacique, excellency, count, etc.

Another possible element of house style — but one which could also very likely be the result of compositor whim - is the emendation of Cooper's punctuation. As John Bush Jones makes clear in his article "Victorian Readers and Modern Editors: Attitudes and Accidentals Revisited," in the mid-nineteenth century it was common practice for compositors to freely rearrange their authors' punctuation. ${ }^{72}$ It is very likely that Cooper's highly idiosyncratic punctuation — which appears as often to have been used to indicate pacing and emphasis as grammatical structure-fell victim to this practice. Cooper's loose comma placement was frequently changed by compositors, who added and left out commas according to their judgment, usually in favor of conventional grammatical usage. The majority of variants in Mercedes of Castile are variants in punctuation.

\footnotetext{
${ }^{72}$ John Bush Jones, "Victorian 'Readers' and Modern Editors: Attitudes and Accidentals Revisited," Papers of the Bibliographical Society of America 71 (1977): 49-59.
} 
Cooper made many revisions to wording while editing the proofs for the A1 text. Variants between MS and A1 show Cooper polishing — never changing the wording substantially, or adding or deleting more than a word or two- but making many minor changes for the sake of removal of superfluity or redundancy, simplification, rewording to avoid repetition, and strengthening of vocabulary. An example of avoiding redundancy occurs in the Preface when Cooper hopes his novel will "render future investigations unnecessary." In his MS he had written "all future investigations," the all itself being unnecessary for the full meaning of the sentence.

Some proof changes, however small, have a significant impact on the meaning of the sentence, and these reveal Cooper's imagination alive with the ever-developing characters and ideas of Mercedes. For instance, after Ozema has disrobed in front of Luis and dressed herself in his turban, very small wording changes are made that increase the sensual nature of the passage. The changed words are underlined:

This act was no sooner done, with a grace and freedom peculiar to her unfettered mind, than she drew the necklace of shells from her finery and advanced a step or two, towards our hero, extending the offering with a half averted face, though the laughing and willing eyes more than supplied the place of language.

This $\underline{X}$ was no sooner done, with a grace and freedom peculiar to her unfettered mind, than she drew the necklace of shells from her person, and 
advancing a step or two towards our hero, extended the offering with a half-averted face, though the laughing and willing eyes more than supplied the place of language.

These changes show the hand of an author at work on proofs. By changing finery to person, Ozema's body is included in the latter. By switching the tenses of advanced/advancing and extending/extended, the immediate action of the passage becomes Ozema's walking towards Luis, seductively drawing out the duration of the walk by making it present tense rather than past. The word act was left out of A1, which I believe was the result of the compositor missing the word. Although it is impossible to know for certain how the word was left out, given the trajectory of Cooper's intentions for the sentence, the word belongs, as it keeps Ozema's unclad body firmly in the reader's mind — as it is, no doubt, in Luis' mind — even as the new sentence begins.

Another significant addition that Cooper made while editing proofs occurs in Chapter 25, not included in this edition. When Luis gives Ozema the cross, he tells her, "Place the chain around thy neck, Ozema, for the precious emblem may help in preserving thee, should the gale throw us on the coast, ere morning. That cross is a sign of undying love" (Cooer's emphasis). The last sentence was added in the proof stage and is significant because it shows why Ozema is so convinced that in this moment she and Luis have been married. Luis's statement refers to Christ's love, while Ozema thinks it refers to his romantic love for her. Cooper very clearly wanted to emphasize the 
misleading nature of Luis's attempts to convert Ozema, as well as the slippery nature of language and interpretation, as his addition here proves.

\section{First British Edition}

Although Cooper sent a set of proofs for to Richard Bentley in London for typesetting the British edition, there is no evidence that he was involved in the details of the edition's printing. In fact, most of Cooper's correspondence with Bentley deals with the publication schedule and issues of copy-right—not stylistic features of the work itself. For this reason, I consider the first British edition to be unauthoritative. Once the work was on the British press, it was fair game for house styling, as collation of the A1 and B1 texts reveals. While A1 renders titles lowercase nearly all the time, Bentley always capitalizes. Cacique is consistently capitalized in the B1 text, as is Count, Lord, Lady, Admiral, etc. B1 also freely changes punctuation — although not so freely as the A1 compositors. For instance, while Cooper sometimes uses the Oxford comma and sometimes omits it in his series_- preferences which, amazingly, appear to carry over into A1-B1 always supplies the missing Oxford comma. B1 also employs British spelling in all cases but connection]connexion, in which case it employs the former, in agreement with Cooper but contrary to A1.

Although most variants in B1 are the result of such house styling, this text does feature certain anomalous variants in wording that are of great editorial interest for establishing a critical edition. In several places, the B1 text features a different wording variant from the A1 text, but one that agrees with the MS. As these are few, I will list them all: 
14.13 arrows, and, there being] A1; arrows, while there was MS, B1

14.26 the young man] A1; the besieged MS, B1

14.36 hill] A1; wall MS, B1

What quite possibly happened is that Cooper edited the first set of proofs, then had Ashmead, the printer, send him two sets of revises (new sets of proofs incorporating the changes made to the first set). Cooper then sent one set immediately to Bentley, who at this point was anxiously awaiting a new round of proofs to continue setting his edition. Then, Cooper probably skimmed over the second set of revises to see how his changes had been incorporated. It was likely at this point that he made a few final changesthose listed above. These were incorporated by A1 because, residing in Philadelphia during publication, Cooper could quickly direct that printer to incorporate the changes in the revises. Therefore, in any locations that feature this pattern, A1 is almost certain to be authoritative.

The first change in particular is indicative of an author wishing to improve his work. Here, Cooper is actually fixing a mistake made by the compositors. The MS final reading is

In the angle were several large fragments of rock that could afford shelter against arrows, while there was a sufficient space of green sward before them, on which a knight might well display his prowess. When in 
possession of this position, our hero felt himself strong, if not impregnable, since he could be assailed only in front.

However, the compositor missed the sentence break before "When," fusing the two sentences and creating a run-on:

In the angle were several large fragments of rock that could afford shelter against arrows, while there was a sufficient space of green sward before them, on which a knight might well display his prowess when in possession of this position, our hero felt himself strong, if not impregnable, since he could be assailed only in front.

Both the British compositor and Cooper can be seen to be making efforts at emending this error. In the variant listed above, Cooper changes the structure of the sentence: "while there was" becomes "and, there being"—making the run-on a compound sentence. The British compositor changed the comma after "position" to a semicolon in order to make the sentence correct. He had not gotten the corrected revises with Cooper's solution, but he did know the sentence had to be fixed and came up with another solution. The other two changes that are likely corrections to the first revises are also efforts at slight improvements. Changing besieged to young man appears to be Cooper avoiding repetition, as he uses besieged only a few pages earlier in the chapter. (It also seems that Cooper was particularly fond of the word, and may have been aware of the fact; the same phrase occurs numerous times in The Last of the Mohicans during the siege of Fort William Henry.) Lastly, changing wall to hill simply makes more sense: Luis and 
Ozema are, indeed, hunkering down near a rock outcropping, which is more of a hillwall giving more the impression of a manmade structure than a natural one.

\section{$\underline{\text { V. American Reprints and the } 1859 \text { Townsend Edition }}$}

The American reprints by Burgess \& Stringer and Stringer \& Townsend throughout the 1840 s and 1850 s appear to have been printed from the stereotyped plates that Fagan produced at the time of the A1 publication. No variants were found when collating A1 against the 1852 and 1856 reprints. The 1859 Townsend edition, however, was reset. This text features increased house styling, consistently changing towards to toward, for ever to forever, and substituting American spellings for Lea \& Blanchard's original British spellings. Townsend also changed much of the A1's capitalization, changing the few capitalized instances of cacique to lower case, and consistently capitalizing excellency.

The 1859 edition also supplied any commas that might have been left out but would be considered structurally necessary. For instance, Townsend supplies the Oxford commas missing from the A1 text, as well as any commas missing from consecutive adjectives: for instance, while the A1 reads, "her soft low musical voice," the 1859 renders the passage "her soft, low, musical voice."

Other variants between the A1 and the 1859 text clearly resulted from compositor error. For instance, in "the inhabitants of Hayti ... were said to be but very little darker," the word but was left out of the 1859. In "to usage or to comfort," the compositor left out the second to. Similarly the 1859 compositors set circumstance rather than circumstances, exception rather than exemption, and $d w e l l i n g$ rather than $d w e l l i n g s$. 
While in the A1, "the danger drew nearer," in 1859 it "grew nearer." These were very clearly the result of compositors misreading their copy rather than author revision.

Therefore, although the 1859 text is interesting in tracking the history of Mercedes, it is not considered authoritative.

\section{First French English-language Editions}

Collation of the Baudry and Galignani editions against each other reveals no variation; they were printed from the same setting of type, and no changes were introduced into the plates of either-if, indeed, the publishers had plates made for the novel, which is uncertain. Therefore, when I speak of the text of both editions, I refer to it as F1 alone, and mean both Galignani and Baudry.

The F1 text was undoubtedly set from the B1. Correspondence in the Richard Bentley archive reveals that Galignani was in the habit of purchasing English-language books from Bentley to sell or reprint in Paris, ${ }^{73}$ and collation of the B1 and F1 texts corroborates that relationship: very few changes were introduced in the F1 resetting. French compositors appear to have clung very closely to their copy, adopting all of Bentley's styling, as well as its readings from earlier proofs (wall and besieged). Most variants between the two are almost certain to be compositor errors. For this reason, I do not consider the F1 text authoritative. Additionally, there is no evidence that Cooper communicated with Baudry or Galignani regarding publication of Mercedes; although Baudry and Cooper wrote each other in the late 1820 s and early 1830 s, no

${ }^{73}$ Colburn and Bentley, letters "To Messrs. A. \& W. Galignani, Paris" in The archives of Richard Bentley \& Son 1829-1898, British Library collection, reel 39, vol. 81 (microfilm published by Chadwick-Healy, 1976): 9 Sept. 1831 (pg. 63); 27 Sept. 1831 (pg. 66); 4 Oct. 1831 (pg. 67); 27 Dec. 1831 (pg. 72); 17 Mar. 1832 (pg. 80); 30 Mar. 1832 (pg. 81); 19 April 1832 (pg. 82). 
correspondence survives beyond those years to give evidence of an ongoing relationship. ${ }^{74}$ Thus, while the $\mathrm{F} 1$ text is of interest in terms of tracking the transmission of Cooper's text to Europe, it is not itself a source for authoritative readings. $\underline{\text { VII. Translations }}$

Although translations of Mercedes are not authoritative representatives of the text, they are fascinating in that they show how the text spread throughout the world. Because of the wording variants between A1 and B1 that resulted from Bentley not receiving the later proofs, I can look at the corresponding words in the translations and tell which English-language editions were used for their preparation. While in A1 an arrow strikes the hill behind Luis, in B1 it hits the wall—as seen in the collation entries listed above. The French Defauconpret translation uses the word rocher in place of wall]hill, and this word's kinship with rock leads me to believe it was translated from either the B1 or F1 texts.

To test this, I checked the few B1-F1 variants that could be distinct enough in meaning to check against the translations. While in B1, Luis fancied he was complying with the wishes of Columbus, in the F1 he is complying with the wish of Columbus. Defauconpret rendered the passage thus: "...en les lui faisant répéter il s'imaginait ne faire autre chose que se conformer aux vues de Columb." Vue means the sight or vision, in a metaphorical sense; and vues is the plural of vue. The plural form being used in both the B1 text and the translation suggests the likelihood that Defauconpret used the B1 text, and not the F1, for his translation.

${ }^{74}$ Several letters from Baudry to Cooper are housed in YCAL, dated 1826 and 1831. 
The other notable variant indicates the origin of the Spanish translations: when Luis is defending Ozema against the Carib warriors, in A1 he is referred to as the young man, and in B1 he is the besieged. Both the 1841 O' Crowley and the 1863 Perez Spanish translations certainly used the A1. O' Crowley used el joven, which literally means "the young man." Perez used el mancebo, which means the same. In place of wall]hill, both translations employ el montecillo, which means "hill," or more literally, "little mountain."

Although I was unable to acquire and examine the Frankfurt German translation of Mercedes, by using these same methods I was able to identify the origin of the Stuttgart translation. For the young man]the besieged, this translation has Der Belagerte, which means precisely "the besieged" in German, indicating that the Stuttgart translation, too, was likely derived from either the B1 or F1. The other variant, wall]hill, confirms

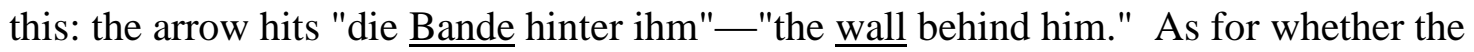
translator used the B1 or F1, it is probable that, like Defauconpret, he also used the B1. For the same B1-F1 variant abovementioned, wishes] wish, the Stuttgart text reads, "nach dem Wunsche Columbus handle." Wunsche is the plural form of wunsch, which means "wish," again matching the B1 plural, wishes.

Thus, I was able to reconstruct the journey the text of Mercedes of Castile took from manuscript, through the proof stages, through the printed English editions and translations. I present it below in the form of a stemma: 


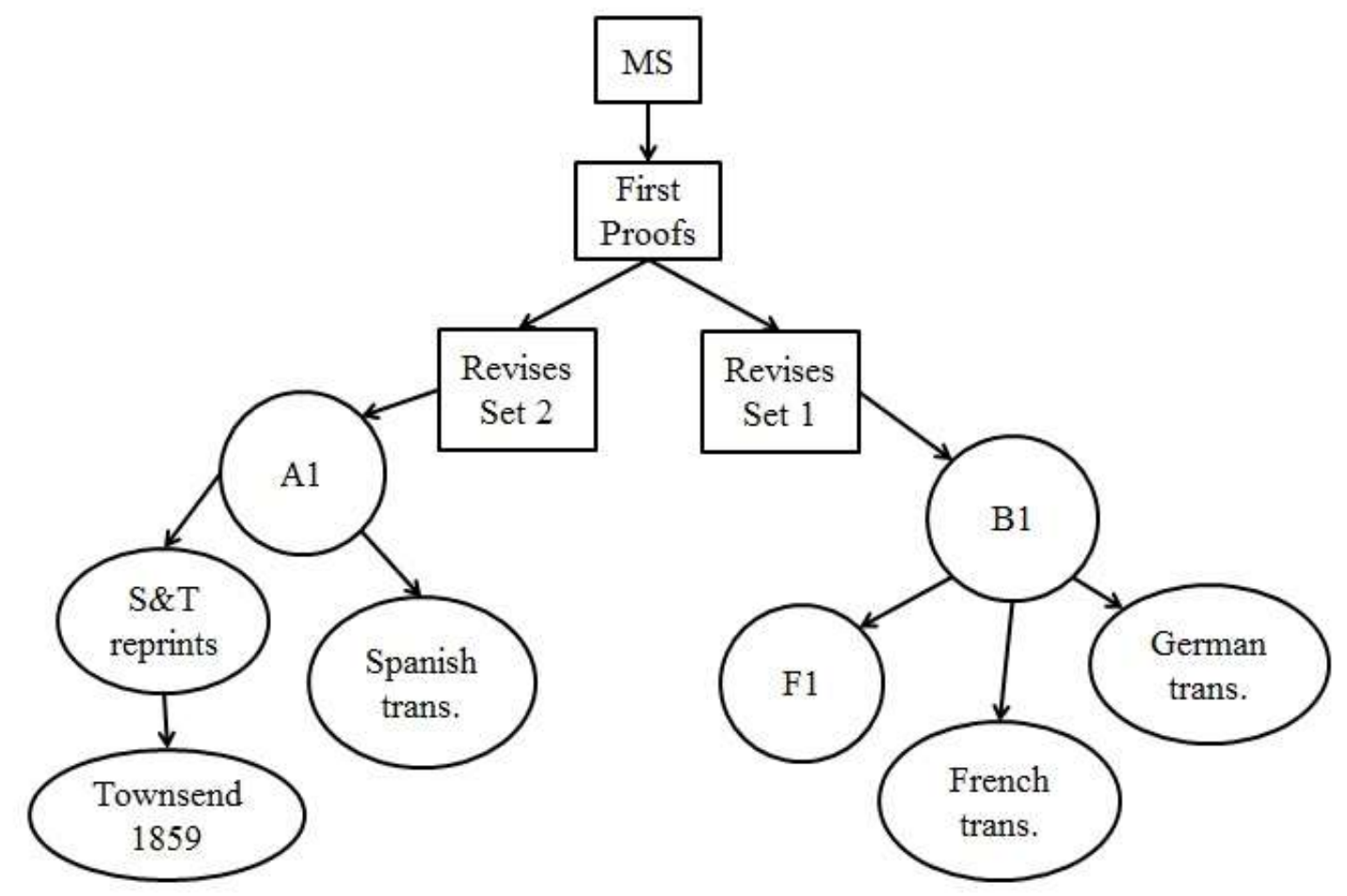




\section{Editorial Principles}

\section{$\underline{\text { I. Wording Variants }}$}

In cases where the wording is different enough to indicate that Cooper made the change during revision of the proofs, I adopt the A1 reading. In cases where the change appears to have been the result of compositor error-such as misreading Cooper's handwriting, leaving out a superlineated word, or accidentally setting a cancelled wordI adopt the MS reading. For variants in which B1 retains readings from the MS that were changed in A1, I adopt the A1 reading, under the assumption that these resulted from Cooper's editing a different set of proofs.

\section{Punctuation}

Cooper demonstrated a distinct desire that his own readings be preserved once his manuscripts arrived at the printer. In 1822, Cooper wrote to John Murray, his publisher in London at the time, concerning the printing of The Pioneers. Cooper gave Murray leave to edit his work, as the author had not had time even to read through the manuscript before sending it for publication. Still, he clearly had his reservations:

...if you find any errors in grammar or awkward sentences you are at liberty to have them altered-Though I should wish the latter to be done very sparingly, both because that one mans style seldom agrees with anothers, and because a similar liberty was abused to a degree in 'Precaution,' that materially injured the book. ${ }^{75}$

Cooper only made this concession because he himself had not had the time to go over his work, and it is clear that he saw the interference of others as harmful. Furthermore, his

\footnotetext{
${ }^{75}$ Cooper to John Murray, 29 Nov. 1822; Letters I, 85.
} 
publishers' reassurances to him over the years indicate Cooper's continuing concern in this matter. While publishing The Spy, Colburn \& Bentley wrote Cooper, "with respect to the introduction and corrections in The Spy we assure you that they shall be carefully superintended while in the press by a competent person." ${ }^{76}$ These publishers made a comment to the same effect about proof revisions in The Bravo, and similar reassurances are present in the correspondence between Cooper and his stereotyper, John Fagan, well into the 1840 s. $^{77}$

I believe this desire extended to punctuation, which Cooper took care to edit while revising his MS. However, punctuation is problematic in that I cannot conclusively tell which changes were introduced during typesetting and which were altered by Cooper in the proofs. Without having the proof sheets in hand, the only option left has been to analyze each punctuation variant to determine whether it was more likely Cooper's change or the compositor's. This endeavor necessitated a degree of familiarity with Cooper's punctuation habits, which I developed over the course of working closely with the MS, as well as an awareness of compositor practices. Knowing that compositors frequently took punctuation revision into their own hands, for commas and similar marks I usually adopt Cooper's MS reading. In cases where I judge the A1 punctuation to be characteristic of Cooper and where Cooper evidently made changes in the proofs in proximity to the punctuation variant in question, I adopt the A1 reading, under the suspicion that while editing for wording Cooper also took the opportunity to edit his punctuation. Where the MS clearly features what would constitute a punctuation error

\footnotetext{
${ }^{76}$ Colburn \& Bentley to Cooper, 21 April 1831; MS: YCAL.

${ }^{77}$ John Fagan to Cooper, 2 Feb. 1848; MS: YCAL.
} 
(such as lack of end punctuation due to hasty revision of a sentence or running against the edge of the page), I accept the A1 correction based on the belief that Cooper did not intend for such errors to be part of the final published novel.

A particularly problematic punctuation pattern is the frequent A1 insertion of semicolons before conjunctions in sentences with multiple other commas. The editors of the Cooper Edition's Pathfinder deemed these to be Lea \& Blanchard house style ${ }^{78}$; the editor of the Cooper Edition's Deerslayer, on the other hand, believed them to be characteristic of Cooper's punctuation habits. ${ }^{79}$ After analyzing the MS, I have determined that although Cooper does occasionally use semicolons in this way, he more often uses them to set off lengthy and significant subordinate clauses, as in the following: "Her answers were less intelligible, but Luis thought they never could be sufficiently full; flattering himself, the whole time, that he was only laboring to comply with the wishes of Columbus.. ${ }^{80}$ Furthermore, the insertion of pre-conjunction semicolons is so common in A1 and so uncommon in the MS that I highly suspect these to be house styling. Therefore, unless a semicolon is highly likely to be Cooper's addition, in these instances I retain Cooper's punctuation, which is usually a comma.

\section{Capitalization}

Cooper appears to have capitalized according to his whim while writing, especially in the case of titles. In Mercedes of Castile, titles are very important, as many of the principal honorific characters are nobility or royalty. After Queen Isabella agrees

\footnotetext{
${ }^{78}$ James Fenimore Cooper, The Pathfinder, or The Inland Sea, eds. James Franklin and James P. Elliott, for The Writings of James Fenimore Cooper (Albany: State University of New York, 1981) 478.

${ }^{79}$ James Fenimore Cooper, The Pathfinder, or The Inland Sea, eds. Beard, Elliott, and Lance Schachterle, for The Writings of James Fenimore Cooper (Albany: State University of New York, 1987) 568.

${ }^{80}$ Present edition, pg. 10.
} 
to sponsor Columbus's voyage, he becomes an admiral, and this title is significant, much having been made of his lack of noble blood in the early chapters of the novel. Furthermore, the novel includes both Spanish and Native American nobility. Whether Cooper wished for the latter to be capitalized or not could indicate his attitude towards the relative equality of the two peoples. As such, investigation of capitalization was vital for establishing my edition.

Both American and British publishers appear to have changed Cooper's capitalization according to their own house standards. The B1 text is noteworthy in consistently capitalizing titles, while A1 usually renders them lowercase. Because of the clear presence of house styling for capitalization, I decided to take my guidance in capitalizing from the MS itself.

In order to establish Cooper's capitalization preferences, I surveyed how many times certain titles were upper- or lowercase, noting their usage as well. In certain cases, Cooper demonstrated a clear preference. For instance, Marchioness of Moya is consistently capitalized, and Daughter Marchioness is capitalized seven out of eight times. Titles that list the territory of rule after them are always capitalized, as in King of Aragon. When a royal is addressed with his or her title, that title is also always capitalized, as in the following:

my Lord King

Sir King

Your Highness

Madam 


\section{Señora}

dearest Princess

Likewise, in Your Highness, the word Your is capitalized five out of six times. When Columbus is spoken of as the admiral, admiral is lowercase most of the time. Although occasional exceptions to the rule occur, in these cases I have adopted Cooper's demonstrated preference.

Unlike the above, in many cases of capitalization Cooper's MS did not display a clear preference. Royalty referred to in the third person, when the persons are distant, are usually lowercase, as in the queen or the king; however, when the queen is in the room or spoken of in a particularly reverent way, she may become "the Queen." In the case of the the king and the queen, Cooper appears to leave the titles uppercase half the time and lowercase half the time. A similar case occurs in the case of your excellency, when Luis de Bobadilla is addressed, which Cooper renders uppercase 3 out of 5 times in my chapter. In such cases where Cooper did not display a preference, I retain his MS reading, thus also preserving the more- or less-reverent tone Cooper invoked with his capitalization in isolated instances.

The word cacique is particularly problematic — not least because Cooper's capital 'c's are distinguished from lowercase 'c's only by their size, Cooper not taking great pains to exaggerate in either case. According with their usual practices, A1 typically leaves the word lowercase, and B1, uppercase. When speaking of caciques in general, Cooper consistently leaves the word lowercase in his MS; however, when using the word to refer to Ozema's brother Mattinao, Cooper capitalizes 9 out of 22 times, thus only exhibiting a 
slight preference in favor of lowercase, but enough to leave Cooper's certainty in doubt. Therefore, for cacique I have relied not only on the MS but on A1 to guide me. A1 typically renders the word lowercase, but in certain instances it does capitalize the word. Because A1's capitalization of cacique is so atypical (3 out of this chapter's 27 instances being uppercase in A1), I strongly suspect that this capitalization was triggered by changes Cooper himself made to the proofs. Thus, for cacique, I accept Cooper's MS reading unless A1 capitalized.

\section{Spelling}

I am retaining Cooper's spellings, both those standard for the time period as well as his antiquated spellings. Following the example of the Cooper Edition, I have used Webster's 1828 Dictionary of American English ${ }^{81}$ to ascertain contemporary spellings, and the Oxford English Dictionary ${ }^{82}$ to identify the time periods where Cooper's obsolete spellings were current. Whenever I found his spelling represented in OED, I chose to incorporate it in my edition. Consequently, spellings such as garlick, publick, vallies, and bawble are preserved. This decision signals a departure from typical Cooper Edition policy_which adopts only those spellings that were acceptable in the 19th century. I have chosen to retain even Cooper's antiquated spellings, firstly because they were his intentions, and secondly because in this novel in particular, the antiquated spellings help to create an old atmosphere appropriate for 1492. They also reinforce the sense of the novel being a historical document, which Cooper is at pains to emphasize.

\footnotetext{
${ }^{81}$ Noah Webster, An American Dictionary of the English Language (New York: S. Converse, 1828) facsimile by the Foundation for American Christian Education, San Francisco, CA, 1989.

${ }^{82}$ Oxford English Dictionary, January-April 2014 <www.oed.com>.
} 
Certain antiquated spellings, such as unseparable, may appear to the reader to be incorrect. I have adopted no incorrect spellings in this edition; the reader may refer to the "Spelling Variants" list, which specifies the spellings that are antiquated, and therefore adopted, and those that are clear misspellings.

Frequently, Cooper misspells words in such ways as they were never spelled. For instance, Cooper often spells their as "thier," which is simply incorrect. In another instance, he misspells a word in such a way as to make it essentially a different word: one example is when he spells several as "severel," or accessories as "accessaries." In these cases, I adopt the spelling for Cooper's intended word.

\section{$\underline{\text { V. Compound Words }}$}

Cooper's practices for writing compound words are largely inconsistent. He often renders as two words compound words that are standardly merged. In certain cases he is consistent, as when he divides the following into two words: every thing, any thing, green sward, and new comer. For all such words I keep Cooper's rendering of the word. In one case I have chosen to adopt the standard, departing from Cooper's reading: Cooper writes "black guards" for the word blackguards. I have used blackguards for my edition, because Cooper's intention was clearly to indicate a meaning along the lines of knaves, cads, and rogues — all synonyms for blackguards — rather than guards who are black.

In the case of compounds that his publishers hyphenated, Cooper was considerably less consistent. In these cases, I have conducted a survey of all instances of each word in the novel. Where Cooper displays a preference, I adopt his preference. For instance, Cooper spells high born as two words three times, but hyphenates it once. 
Similarly, out of two instances of mid winter, Cooper makes it two words both times. For these, I have adopted Cooper's clear preference. In cases where Cooper does not display a preference, as in the case of sea weed, I adopt Cooper's spellings as he writes them in the MS.

In the case of compound adverb-adjective constructions modifying a noun, Cooper occasionally demonstrates attention to the need for a hyphen. For instance, he does hyphenate all-engrossing when it modifies a noun but writes it all engrossing otherwise-following standard grammatical practice. He is less consistent with simpleminded (as a compound adjective preceding a noun), which he hyphenates once out of three times. I have accepted all Cooper's MS readings in these cases, as they represent his intention. 


\section{Textual Notes}

1.5 the statements] In his MS, Cooper cancelled the word all, which the compositor mistakenly set.

1.21 must fain submit] Cooper added above the line the word fain, which the compositor missed while setting type.

1.30 Meridian] Capitalization of meridian was decidedly nonstandard, but it was done as late as the 18th century, especially in poetical usage (OED). Cooper's capitalization has been retained in this instance, as it adds to the antiquated style that the author cultivates in this work.

1.34-2.2 This little peculiarity $\{\ldots . .$.$\} rendered easier and more agreeable.] This portion$ was entirely excised by Bentley in the first British edition; consequently, it also fails to appear in the French English-language editions produced by Baudry and Galignani that year, as well as being omitted from the French translations. This editorial choice is significant in that it shows how thoroughly embroiled Cooper was in his Press Wars at the time - so much so that he chose his preface for Mercedes as a place to continue his attacks. Bentley's decision to edit this out could suggest he had doubts as to how helpful these inflammatory remarks would be for book sales. More conservatively interpreted, it shows that the comments were particularly suited for American publication-as all Cooper's editor enemies were American-but not for British. This is likely the case with respect to Cooper's discussion of when to begin a new calendar day, which, if - as his MS read before he cancelled the sentence-England already used this method, would, indeed, be inappropriate. There is no documentary evidence as to whether Cooper sanctioned Bentley's excision or not, but as these lines are a critical part of the MS and first American edition, they have been retained in the present edition.

3.3 Fancy's] Here, Cooper clearly is using Fancy in the Romantic, Coleridgean sense of a deity-like artistic inspiration; it is personified here. To render it lowercase understates its significance. This was likely a compositor error, and one that persisted over the course of all subsequent editions.

3.30 your Excellency] Cooper's demonstrated preference for your in this context is to render it lowercase, whereas he demonstrates no preference for excellency. For excellency, therefore, the MS form has been adopted to allow for Cooper's whim in this matter. (See "Editorial Principles: Capitalization.")

3.35-36 Sancho, of the Ship Yard Gate] The MS reading is essential in this case, and it is unlikely that Cooper changed it in proofs. "of the Ship Yard Gate" functions as Sancho's title, just as "de Valverde" is that of Mercedes, and "de Bobadilla" is that of Luis. Unlike the latter two, however, Sancho is a sailor who has no family name but was found in a basket by the gate of the shipyard of Moguer, Spain. It is crucial that ship, yard, and gate 
be capitalized, as they are meant to mock upper-class titles, thus supporting Sancho's overall disdain for the aristocracy. What likely threw off Cooper's editors was the fact that the conventional rendering of shipyard was "ship-yard," and wanting to retain the hyphen, they found themselves at a loss with regard to the capitalization. The A1 comma has been retained here, because its absence in the B1 text suggests it was not in the proofs sent to Bentley. It is therefore likely a comma Cooper added in a later proof stage.

Furthermore, it could be a rhetorical comma meant to increase the magnanimous sound of Sancho's title.

3.43 A Castilian noble cannot envy even a Haytian Sovereign.] It is worth noting that Cooper's MS capitalization of sovereign lends additional stateliness to "a Haytian Sovereign," stateliness which A1 robs it of when it lowercases the word. The A1 compositor also appears to have left out the word even. While it is possible that Cooper could have struck through this word while editing proofs, it is equally possible that the compositor, after setting the very similar word envy, saw another word with 'e', 'n', and 'v' thought he'd already set it, and left it out. The MS reading of "even a Haytian Sovereign" preserves the regality Cooper affords Haitian royalty. It also accords with the trend towards capitalization of Cacique between the combined MS and A1 proof corrections (mentioned in "Editorial Principles: Capitalization").

4.1 my lord; 4.2 our Gracious Lady; 4.4-5 His Highness] It is likely that in the initial drafting of this passage, there were so many titles that Cooper began to capitalize more than he typically would have. Here, my lord refers to Columbus, and in Columbus's most frequent title, admiral, Cooper usually makes it lowercased. He tends to lowercase Columbus's titles, and he probably reduced the capitalization in this passage while editing proofs in order to better set off Isabella's titles, which are consistently capitalized. With respect to "His Highness, King Guacanagari," in various surveyed chapters from the beginning, middle, and end of the MS, Cooper demonstrated a decided preference towards capitalizing both Highness and its preceding pronoun. Furthermore, capitalizing His Highness here has the effect of placing Guacanagari and Isabella on a level, emphasizing the conflict that must ensue when the two cultures collide.

4.3 queen] Cooper capitalized queen in the MS, but he so consistently writes it lowercase in this usage - speaking about a generic, not specific, regent - that its appearance lowercased in A1 could be the result of Cooper's editing proofs.

4.7 heads of the canoes] Cooper's MS reads "head of the canoes." The A1 compositor either didn't see the 's' on canoes, or, upon realizing the MS construction did not make sense, he dropped the 's' to make a reading that did. I have chosen to correct the passage the other way-by making head plural to match canoes. The natives having multiple canoes, this method seemed the most likely to reflect Cooper's intention. 
4.27 Mattinao ] The MS comma appears to have been residual punctuation from something Cooper ended up canceling; his strike-through simply did not extend far enough. See page 20 in the "Textual History" for a thorough discussion of this variant.

4.36 word, "Ozema,"] At one point in the MS, Cooper uses quotations around "Ozema" when speaking of it as a word, but neither he nor his publishers consistently do so. The present edition adopts Cooper's technique for all such cases for the sake of clarity; it adopts the standard of placing the comma before the end quotes, which appears to have been Cooper's habit, as well.

4.42 the presence of man for centuries, had] Not only is the MS comma placement characteristic of Cooper, but it also removes the possibility of ambiguity here, which the A1 reading introduces: "...the presence of man for centuries had deprived it of all its ruder and more savage features." Here, "for centuries" could easily modify "the presence of man" or "had deprived it of...." For this reason, Cooper's reading makes more sense, and it is unlikely that he would have cancelled the comma while editing proofs.

5.2 owners; the flowers bloomed, in mid winter; and] Cooper used all commas in this sentence, but as there are commas within the series items, semicolons have been used to clarify Cooper's meaning. Other places in the MS indicate that Cooper used semicolons in a series; therefore, this step is not one that Cooper would likely have objected to. His publishers attempted to do this, but they appear not to have completed the task, only using a semicolon after the first item in the series. The MS comma before "in mid winter," has been retained, as Cooper often uses this particular placement for emphasis.

5.32 town, below the river] The sentence reads, "Here he reached a cluster of rustic dwellings that occupied a lovely terrace on a hill side, where they overlooked the larger town, below the river, and commanded a view...." The MS placed the comma after below, which was likely a mistake, the real intention being to put it one word earlier: after town. This placement makes structural sense while also preserving the leisurely pace of Cooper's description.

5.40 probable $]$ Because B1 matched the MS in this reading, and A1 was the only witness with the comma, there remains the possibility that the early proof stage, which went to Bentley, left out the comma, and then Cooper added the comma in a later proof. However, because of the syntactic awkwardness of this comma, it was more likely added by an overly exuberant compositor while setting proofs, and then the British compositor removed it for not making sense. The MS reading is therefore adopted in this case as more likely to have been Cooper's intention.

6.7 anteroom] This word is split between lines and hyphenated in the A1 and B1 texts; however, according to Noah Webster in 1828, the word is unhyphenated. 
6.20-21 take up, and renew,] Cooper added these commas while revising his MS; this is evident because they are in darker ink than the running text. The fact that Cooper deliberately added these shows that he very much intended to have them, but they were left out in typesetting.

6.24 reverted] Here, the compositor misread Cooper's handwriting, taking the ' $v$ ' for an 's' and the 'e' for an 'o,' producing the incorrect reading - but one that would easily have passed Cooper's inspection of proofs - of resorted. The 'e,' on closer examination, was discernable, as Cooper had gone over his MS and emphasized his 'e's by adding loops to them to make them clearer. He did so in the case of reverted, making the correct reading clear upon close examination of the MS.

7.34 without being reduced to comparing] The A1 reading, "without being reduced to compare," is grammatically incorrect, and I judge it more likely the result of compositor error than of Cooper's revision.

7.35 Ozema; but, still] This placement is such that Cooper could have added the semicolon while editing proofs: the semicolon mark sets off a significant second half of the sentence, which declares the resemblance between Ozema and Mercedes to be undeniable. As Cooper often used semicolons to denote significant portions of his sentences, the A1 semicolon in this case is likely in accord with his intentions.

8.13-14 there remained nothing but for the parties to express] This reading is restored from the MS, which - as a result of various cancellations and insertions above the linewas incorrectly ordered during typesetting. The diplomatic transcription of the MS reads thus: "there remained nothing $<$ for all $>\uparrow$ but for the $\downarrow$ parties $<$ but $>$ to express." In other words, it first read, "there remained nothing for all parties but to express," before Cooper crossed out for all, added but for the before parties, and cancelled but: "there remained nothing but for the parties to express." The compositors, however, missed the added but and neglected to cancel the original but, yielding "there remained nothing for the parties but to express."

8.33 unseparable] This spelling was in Cooper's day considered obsolete, the standard spelling being "inseparable" (Webster 1828). It was, however, an acceptable form in earlier times (OED); it is thus retained in the present edition.

8.41-42 exhibit. \{paragraph break\} While] Although in the case of paragraph breaks it is difficult to say whether the author, editor, or compositor might have been responsible, in this case the break that was introduced in the A1 text supports Cooper's own pattern of increasing the sensual nature of this passage. By breaking the paragraph here, Luis's thoughts of Mercedes are very clearly interrupted by Ozema's disrobing. The break puts Ozema's action in the spotlight, and the drama of the moment is significantly increased from that in the MS, which has the two passages as one paragraph. 
9.20 dress and] The MS reads "examining his dress, not failing," with and the ornaments he wore superlineated above dress. The compositor misplaced the comma, thinking the addition should go after the comma, when it was intended to go before.

10.6 meaning, that he; 10.33 between the two; 15.5 as all will understand who; 16.27 sun, and the head] In these readings, Cooper left out the bolded words in his MS, without which the sentences either do not make sense or are ungrammatical; it is likely they were restored by either a compositor while typesetting or by Cooper in proofs. As Cooper closely oversaw publication of Mercedes, staying in Philadelphia during its printing, it is likely that wording revisions such as these would have been brought to his attention by the printer.

10.33-34, 35 so strong, as - after some allowance had been made for dress and other sufficiently striking circumstances - to render them almost identical.] In his MS, Cooper moves the clause (set off with dashes in this edition) from the end of the sentence using an arrow and forgets to punctuate it. If the clause in question had been written in the regular course of drafting, however, Cooper would probably have set it off in some way. This edition employs dashes for the purpose, as Cooper did use dashes in this manner elsewhere in the MS.

11.4 far] The word far was added above the line, and the compositor apparently missed the addition while typesetting.

11.15 hawk's-bells] Cooper does not appear to be consistent with his rendering of this word. Out of nine times, in four instances Cooper renders hawk's plural, hawks', to match the plural bells, and he uses the singular form when only one bell is meant. However, in one case he forgets the apostrophe altogether, and in the remaining cases he uses hawk's bells, much more closely approximating the publishers' chosen form: hawk'sbells. Although Cooper seems to have begun with the intention of preserving plural and singular forms, he ended up forsaking the practice. He probably wasn't exactly sure how to render the word and ended up changing his mind over the course of the passage. For the sake of clarity, the present edition uses the A1 reading: hawk's-bells. This spares the reader the grammatical consternation of encountering "twenty hawk's bells," and trying to decide whether the apostrophe was misplaced or not, and whether Cooper means twenty bells or the bells of twenty hawks. Being flummoxed by the circumstance, Cooper would likely have sanctioned this decision.

11.24 thou] The MS capitalization of thou results from the word being the first in the sentence before Cooper added a clause before it, forgetting to edit the case of Thou. Cooper was not in the habit of capitalizing thou; therefore, the printed editions in this case probably reflect his intentions.

13.5 Christian] Cooper does not appear to take particular care with capitalization of this word. He capitalizes half the time and does not the other half. Furthermore, his very 
indistinct 'c' sizes sometimes make it difficult to tell which he means. As Cooper does go out of his way to capitalize unusual words, such as Free Trade and Commerce, he probably did intend for Christian to be capitalized.

13.31 bundle ] Cooper's MS originally placed a comma after bundle, which appears to have been set during the typesetting of A1 proofs, as it made it into the B1 text. It was then cancelled in A1, likely in a later proof stage while Cooper was skimming this portion of the novel after sending Bentley his proofs. It is an unusual placement of a comma, which is why it is unlikely that Cooper cancelled it in A1 proofs, only to have B1 compositors set it again of their own accord.

13.35 convulsively,] Cooper's MS reads, "...pressed the arm of Luis convulsively, and became the Indian heroine, again." A1 omits the comma, and B1 retains it. Although this, like 13.31, could be an instance of B1 taking its comma from its proofs and Cooper later cancelling the comma, the word convulsively is the third item in a series. As B1 always included the Oxford comma, it is reasonable to suppose that even if A1 had cancelled the comma during composition, B1 would have restored it. The Oxford comma has thus been retained here, as being an MS reading that was lost during typesetting for A1.

13.42 "Caonabo-no-no-no."] Although it is possible that Cooper edited the punctuation of this passage in proofs, this punctuation does not match the pace and intensity suggested by the word murmuring. In the MS, Ozema murmurs, while the punctuation in the A1 and B1 makes her sound more like she is shouting. The MS period has thus been adopted in this edition.

14.2 of feelings] The compositor incorrectly set the word her where Cooper had cancelled it in his MS.

14.13 and 14.14 and, there being $\{\ldots\}]$ See page 23 in the "Textual History" for discussion.

15. 5 as all will understand who] See note for 10.6.

15.17 "No Caonabo-Caonabo-no-no-no."] Although Cooper could have cancelled the second Caonabo in his proofs, the passage actually makes more sense with it. Immediately after the quote, it reads, "Luis understood the first part of this answer to mean that the stranger was not the Carib chief ("No Caonabo"); and the last to signify Ozema's strong and settled aversion to becoming his wife ("Caonabo-no-no-no."). Inclusion of the second Caonabo follow's Ozema's pattern: she several times says, "Caonabo - no-no-no- - in dread of the chief. A compositor likely left out the second Caonabo accidentally, skipping ahead to the no-no-no after setting the first one. 
16.27 sun, and the head] See note for 10.6.

16.33 missive. A second] In the MS, Cooper cancels the comma and conjunction and but forgets to put end punctuation and capitalize the following word, making it unclear that he intended the two sentences to be broken. The compositor for A1 read the passage as one sentence, as well as incorrectly reading an 's' at the end of missive. The sentence break and singular form have been restored in this edition.

17.1 Ozema!"- - Cooper probably meant the dash as a connector from the quote to the rest of the sentence, but placing it before the quotation mark makes it look like Ozema stopped short in her speech. The present edition retains Cooper's dash while shifting its location slightly to better clarify its function. 


\section{Historical Collation}

The historical collation includes all variants between printed editions and the MS. Because the F1 text differs so little from the B1, I am only including it where it differs from B1. Likewise, as the Stringer \& Townsend reprints have no variants from A1, I do not include them. I have not included the Townsend \& Co. 1859 edition, as Cooper, deceased as of 1851, was in all probability not involved in its publication: no evidence exists of his having left instructions for Mercedes's revision, nor do any of the variants between A1 and the 1859 edition appear to be the result of such instructions.

Two categories of variants are included in separate lists. Wording changes between the MS and A1 that are clearly revisions by Cooper in the proof stage are included in the first list: "Alterations from the Manuscript to First American Edition." The second is a list of spelling variants, which is further subdivided into the categories "American/British Forms," "Antiquated Forms," "Compound Words," and "Misspellings."

Asterisks $(*)$ indicate entries with an accompanying textual note, daggers $(\dagger)$ indicate that the variant was the result of compositor misreading, and degree symbols $\left(^{\circ}\right)$ indicate readings that have been adopted to avoid ambiguity. The siglum K (Kingsley) indicates readings that are not present in any of the witnesses but that have been established as being representative of Cooper's intentions nonetheless.

\section{$\underline{\text { Main List }}$}

\begin{tabular}{|c|c|}
\hline 1.3 & $\begin{array}{l}\text { years, touching] A1; years-and well written, too,- touching MS; years, } \\
\text { touching B1 }\end{array}$ \\
\hline$* \uparrow 1.5$ & of omit the statements] MS; all A1, B1 \\
\hline 1.5 & work] MS, A1; Work B1 \\
\hline 1.16 & unusual,] MS; , A1, B1 \\
\hline 1.17 & is, daily and hourly,] MS; $\sim \sim \sim$ A1, B1 \\
\hline 1.17 & American] MS, A1; omit B1 \\
\hline 1.18 & testimony,] MS; $\sim-\mathrm{A} 1, \mathrm{~B} 1$ \\
\hline$* \dagger 1.21$ & fain] MS; omit A1, B1 \\
\hline 1.22 & frank,] MS; ${ }_{n} \mathrm{~A} 1, \mathrm{~B} 1$ \\
\hline 1.23 & Cathay,"] MS, A1; " B1 \\
\hline 1.24 & us; or, rather] MS, A1;,$\sim \sim \mathrm{B} 1$ \\
\hline 1.24 & that $^{2}$ ] MS, A1; which B1 \\
\hline 1.26 & author,] MS, A1; B1 \\
\hline$* 1.30$ & Meridian] MS; meridian A1, B1 \\
\hline 1.30 & M/meridian,] MS, A1; ; B1 \\
\hline $1.30-31$ & and with $\{\ldots\}$ prerogatives $]$ MS, A1; and, with $\{\ldots\}$ prerogatives, B1 \\
\hline 1.34 & historian $\left._{n}\right] \mathrm{MS} ; \sim, \mathrm{A} 1, \mathrm{~B} 1$ \\
\hline$* 1.34-2.2$ & This little peculiarity $\{\ldots$.$\} and more agreeable] MS, A1; omit B1$ \\
\hline 1.35 & critic; but] A1;,$\sim \mathrm{MS}$ \\
\hline 2.5 & discovered, back MS, A1; B1 \\
\hline
\end{tabular}




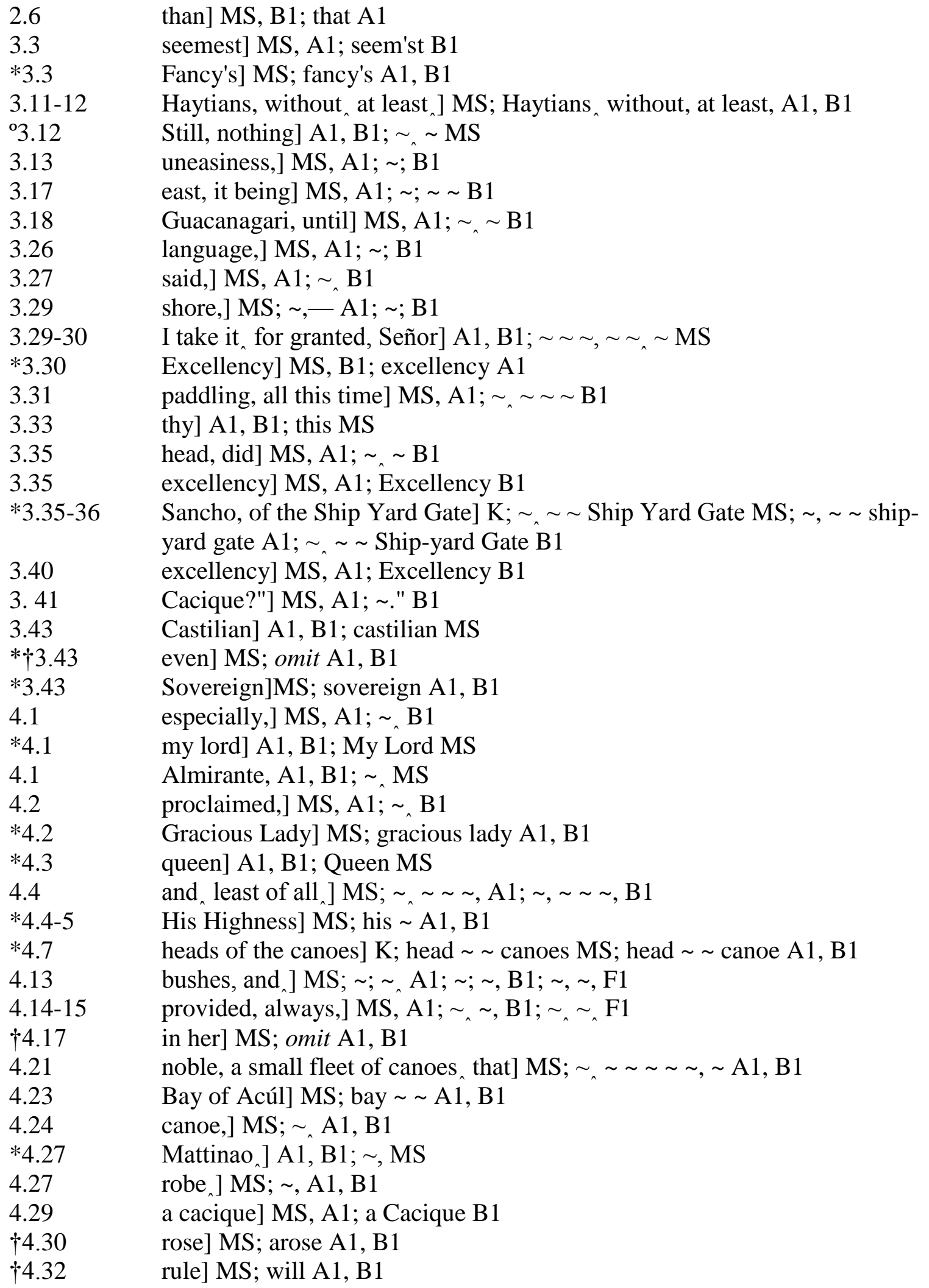




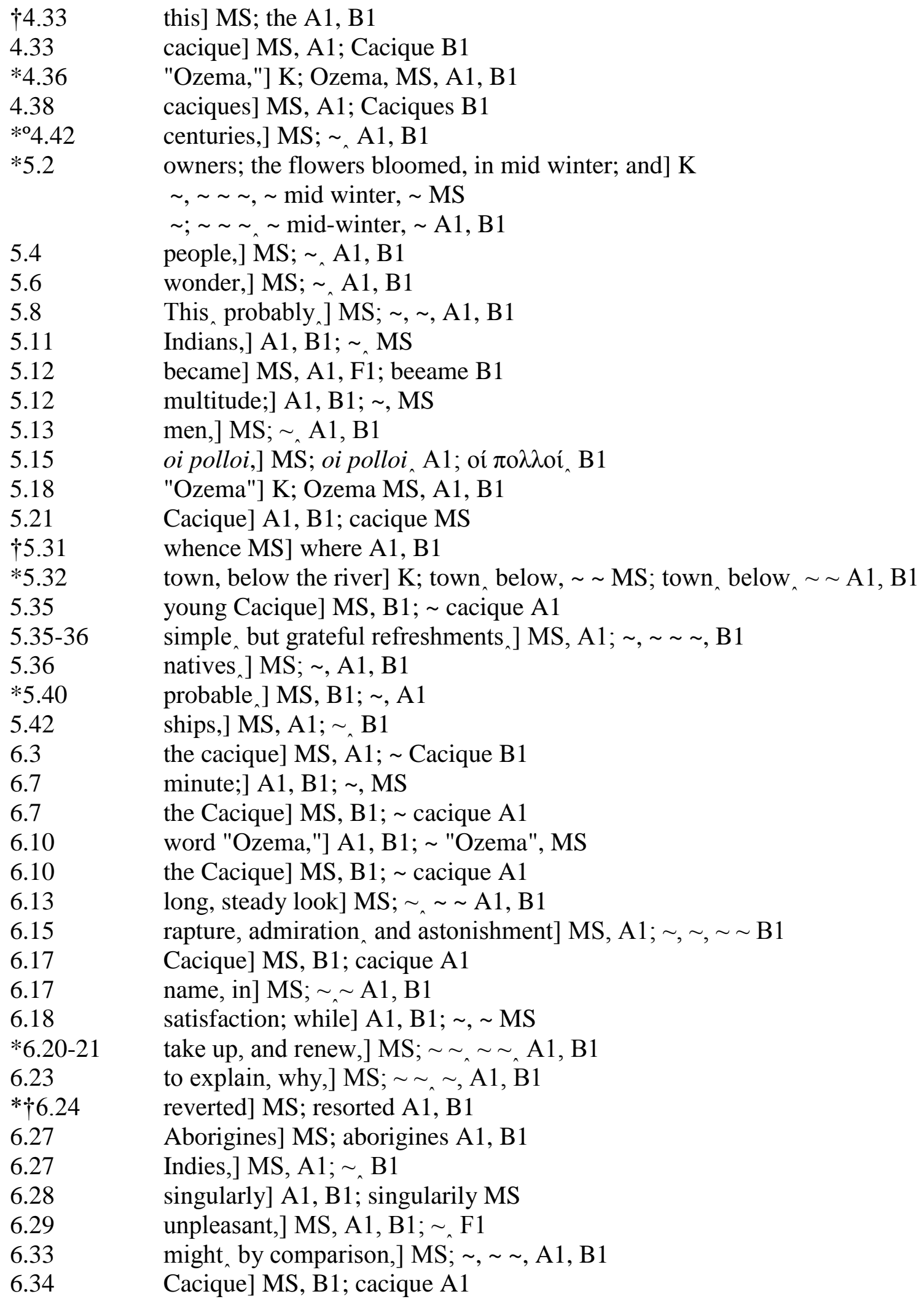


6.35

6.35

6.37

6.42

6.43

7.3

7.6

7.6-7

o7.9

7.11

7.16

7.17

7.18

7.22

7.26

7.29

07.29

7.31

*7.34

$* 7.35$

7.36

7.37

7.38

7.40

7.41

7.43

8.1

8.3

8.4

8.5

8.8

8.10

$*+8.13-14$

8.15-16

8.16

8.17

8.20

8.21

8.22

8.23

8.24

8.25

${ }^{\circ} 8.25$

8.25
According to the laws of Hayti,] A1, B1; MS

a cacique] MS, A1; Cacique B1

circumstances] MS, A1; circumstance B1

are, more or less,] MS; $\sim \sim \sim$ A $1, \mathrm{~B} 1$

the Indians they had yet seen, seemed] MS; $\sim \sim \sim \sim \sim \sim \mathrm{A} 1, \mathrm{~B} 1$

luxuriance $]$ MS; , A1, B1

divine creator] MS, A1; Divine Creator B1

modest, artless, timid and perfect] MS; , , , A1, B1

Still,] A1, B1; MS

Ozema, herself,] MS, B1; , A1

Sandals $]$ MS;, A1, B1

envied, and] MS; ; A1, B1

small, but gorgeous] MS; $\sim \sim \mathrm{A} 1, \mathrm{~B} 1$

female to female,] MS; $\sim \sim$ A1, B1

breathing, than blowing] MS; $\sim \sim \mathrm{A} 1, \mathrm{~B} 1$

well rounded form] MS; well-rounded $\sim \mathrm{A} 1, \mathrm{~B} 1$

expression,] A1, B1; , MS

This resemblance alone,] MS; A1, B1

without being reduced to comparing] MS; compare A1, B1

Ozema; but, still] $\mathrm{K} ; \sim, \sim, \sim \mathrm{MS} ; \sim ; \sim$, A1, B1

strong, that $] \mathrm{MS} ; \sim, \sim \mathrm{A} 1, \mathrm{~B} 1$

one,] MS, A1; , B1

finesse] MS, A1; fineness B1

of a cultivated woman] MS, A1, B1; of omit cultivated woman F1

habits; and] A1, B1; , MS

Nonetheless] MS; Nevertheless A1

striking, and ] MS; ; , A1, B1

Indian to] $\mathrm{MS} ; \sim, \sim \mathrm{A} 1, \mathrm{~B} 1$

What,] MS; A1, B1

enthusiasm] MS, A1, B1; euthusiasm F1

Mercedes_-"] MS; !" A1, B1

step,] MS, A1, B1; , F1

nothing but for the parties] MS; nothing for the parties but A1, B1

the cacique] MS, A1; Cacique B1

below,] MS, A1; B1

fancy. But] MS, A1; ; B1

it, in his visits to the shore,] MS, A1; $\sim \sim \sim \sim \sim \sim$ B 1

simple-minded natives] A1, B1; simple minded $\sim \mathrm{MS}$

whims, in this manner,] MS; $\sim \sim \sim \sim, \mathrm{A} 1 ; \sim \sim \sim \sim$, B1

head, at] $\mathrm{MS} ; \sim \sim \mathrm{A} 1, \mathrm{~B} 1$

and overcome] $\mathrm{MS} ; \sim, \sim \mathrm{A} 1$

and, possibly,] MS, A1; . B1

unlooked-for] A1, B1; unlooked for MS

exhibition] MS, A1, B1; exhibibition F1 


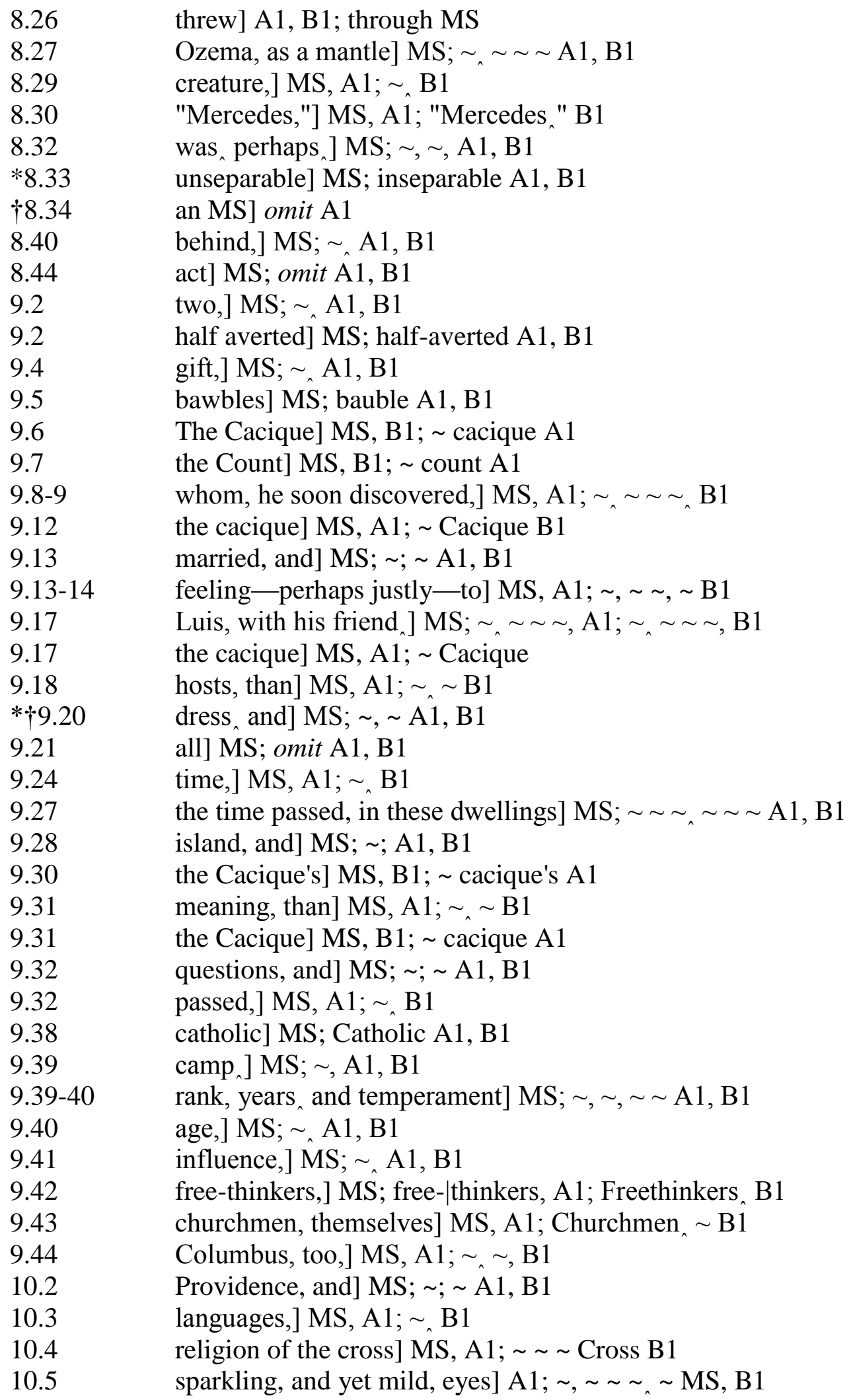




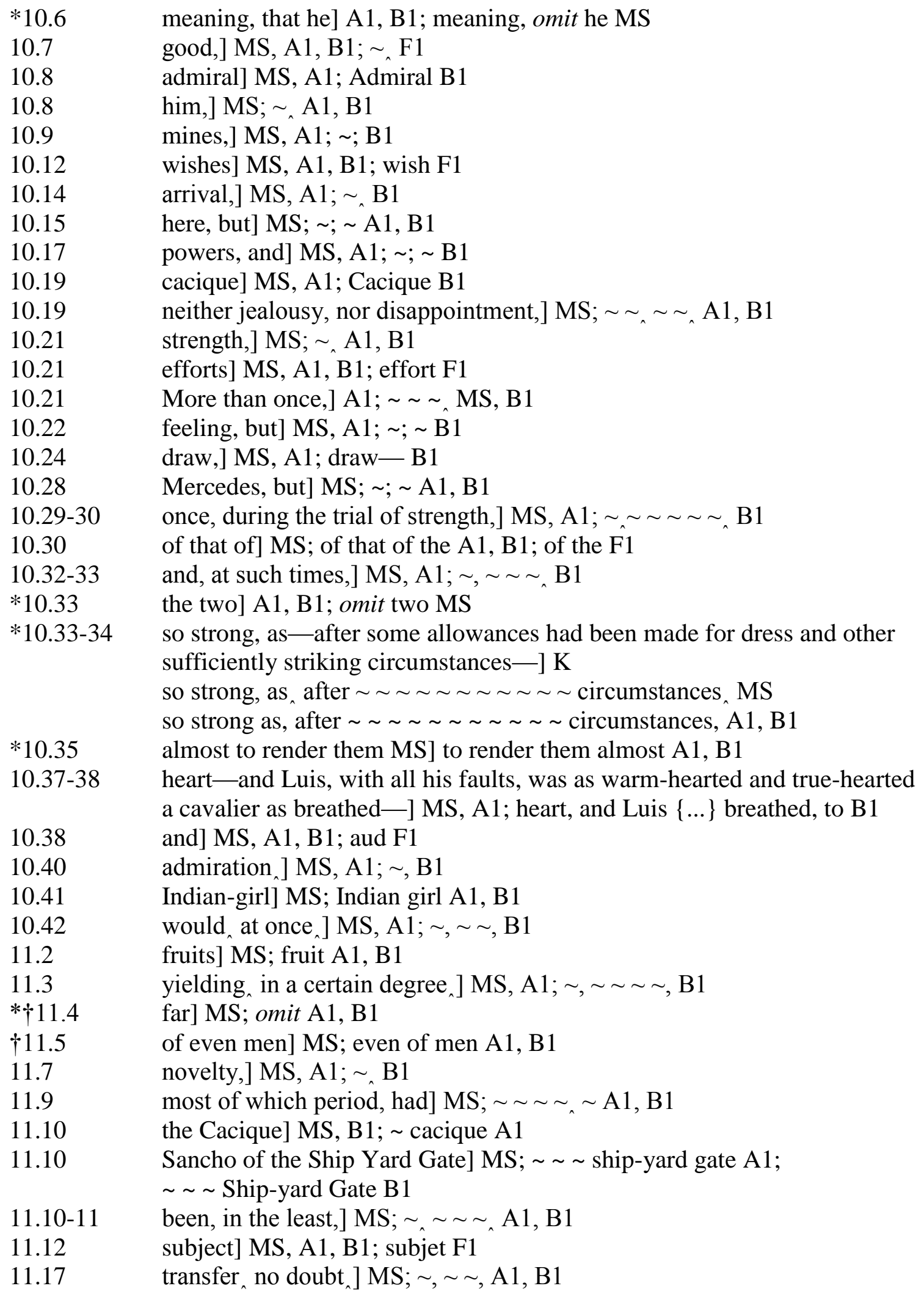


11.18 favorite] MS; favourite A1, B1

11.18

11.19

11.21

11.24

*11.24

11.27

11.28

11.29

11.31

11.31

11.39

11.40

11.41

11.42

11.43

12.4

$\dagger 12.4$

12.5

12.5

12.7

12.10

${ }^{\circ} 12.12$

12.13

12.14

12.16

12.16

12.16

12.18

12.20

12.20

12.21

12.21

12.23

12.27

12.28

${ }^{\circ} 12.30$

12.31

12.36

${ }^{\circ} 12.37$

Free Trade Theorists] MS; free trade theorists A1, B1

equivalents;] MS, A1; , B1

met $_{\text {] }}$ MS, A1; , B1

perceive] A1, B1; percieve MS

thou] A1, B1; Thou MS

our Lord the King and our Lady the Queen] MS;

$\sim$ lord $\sim \sim \sim$ lady $\sim \sim$ A1, B1

Conde;] MS, A1; , B1

By the Mass!] MS; mass! A1, B1

gold,] MS; A1, B1

Excellency] MS; excellency A1, B1

Ship Yard of Moguer] ship-yard A1, B1

market? Ask] MS; market? ask A1, B1

traders,] MS; . A1, B1

Candia, grapes and figs and Greek wine ${ }_{\wedge} \mathrm{K}$;

$\sim$, $\sim \sim$, greek $\sim$, MS;

$\sim, \sim \sim \sim, \sim$ Greek $\sim, \mathrm{A} 1, \mathrm{~B} 1$

Oh! nothing] MS; , A1, B1

Commerce] MS; commerce A1, B1

then is it just] MS; $\sim$ it is $\sim \mathrm{A} 1, \mathrm{~B} 1$; Then it is $\sim \mathrm{F} 1$

St. Andrew my patron] MS; , A1, B1

any thing] MS; anything A1, B1

You see,] MS; A1, B1

chances $]$ MS; , A1, B1

these, her new subjects] A1, B1; $\sim \sim$ MS

business,] MS; , - A1, B1

favor] MS; favour A1, B1

knave ] MS; , A1, B1

"lest] MS, A1, B1; lest F1

Trade] MS; trade A1, B1

gold; whereas,] A1, B1; , , MS

it is right as it is, and] MS; ; A1, B1

purgatory] MS; Purgatory A1, B1

him, who] MS; A1, B1

free, and] MS, A1; , B1

Free Trade] MS; free trade A1, B1

the cacique, and] MS; cacique; A1; Cacique; B1

person,] MS, A1; B1

hero, with his weapons,] A1, B1; , , MS

diversion; while] $\mathrm{A} 1, \mathrm{~B} 1 ; \sim, \sim \mathrm{MS}$

due them] MS, A1; due to them B1

Mattinao $]$ A1, B1; , MS

12.38

'Caonabo'?"] K; "Caonabo"?" MS; 'Caonabo?'" A1, B1 
12.39 Carib cacique] MS, A1; Carrib Cacique B1

12.44-13.1 hero, slowly and sullenly $\left.{ }_{\wedge}\right] \mathrm{MS} ; \sim, \sim \sim \sim, \mathrm{A} 1, \mathrm{~B} 1$

13.1 the cacique] MS, A1; Cacique B1

*13.5 Christian] A1, B1; christian MS

13.6

13.6

$\dagger 13.8$

13.8

13.11

solitary] MS, A1, F1; soilitary B1

individuals $]$ MS; , A1, B1

had reached] MS; omit reached A1, B1

Mattinao,] MS; A A1, B1

Ozema herself,] MS; A A1, B1

13.11

collected] MS, A1, F1; eollected B1

13.14

13.15

13.16

13.17

13.17

princess,] MS; princess; A1; Princess; B1

Carib] MS, A1, B1; Carrib F1

the cacique's] MS, A1; Cacique's B1

conjecture,] MS; A1, B1

Luis'] MS; Luis's A1, B1

$13.20-21$

13.23

13.24

13.25

13.29

13.30

hope, confidence, and petition] MS, A1; , , B1

princess] MS, A1; Princess B1

enemies: no] A1, B1; . No MS

given,] MS, A1; B1

unseen,] MS, A1; ; B1

13.30-31

*13.31

13.34

*13.35

13.36

13.41

*13.42

13.43

13.43

$* \dagger 14.2$

14.4

14.6

that, each moment,] MS, A1; $\sim \sim$ B1

Luis, accordingly,] MS; $\sim$, A1, B1

bundle ${ }_{\wedge}$ A1; , MS, B1

moment,] MS, A1; ; B1

convulsively, and] MS, B1; A1

heroine, again] MS; A1, B1

murmuring — ] MS; , - A1, B1

"Caonabo-no-no-no."] MS; "Caonabo,—no-no-no!" A1, B1

princess] MS, A1; Princess B1

dissent, and] MS, A1; ; B1

of omit feelings] MS; of her feelings A1, B1

and consequently ${ }_{\text {, }}$ MS; , , A1, B1

count] MS; A1, Count B1

14.8

14.9

Luckily ] MS; , A1, B1

*14.13

rocks, and,] MS, A1; ; , B1

$* 14.14$

14.17

14.20

and, there being] A1; while there was MS, B1

prowess when in possession of this position, our] A1;

prowess. When in possession of this position, our MS;

prowess when in possession of this position; our B1

$14.20-21$

14.23

concealed, however,] MS, A1; ; , B1

line,] MS; A A1, B1

war-clubs and] $\mathrm{MS} ; \sim, \sim \mathrm{A} 1, \mathrm{~B} 1$

would kill certainly] MS; , A1, B1

14.26

young man] A1; besieged MS, B1 
14.26

14.29

14.29

14.36

14.38

14.39

14.41

15.4

15.4

*15.5

15.10

15.12

15.12

15.14

15.14

15.17

$* \dagger 15.17$

15.22

15.25

o 15.30

15.31

15.36

15.38

15.42

15.44

15.44

16.1

16.6

16.8

*16.11

16.12

16.13

$\uparrow 16.16$

16.19

16.22

16.24

*16.27

16.29

$* \dagger 16.33$

16.34

${ }^{\circ} 16.35$

16.39

16.40 rocks,] MS, A1; B1

It was perhaps fortunate] MS; , , A1, B1

Caonabo, himself,] MS; A A1, B1

hill] A1; wall MS, B1

assaults] A1; assault MS, B1

shout; whether] MS; , A1, B1

those] A1; there MS, B1

appeared ] MS; , A1, B1

"Ozema"—-Ozema"] MS; "Ozema"_-"Ozema," A1; "Ozema, Ozema" B1 as all will understand who] A1; as omit will understand who MS

princess] MS, A1; Princess B1

this] MS, A1; the B1

fierce looking] MS; fierce-looking A1, B1

"Caonabo?"-] MS; ?" A1, B1

Luis of] MS; , A1, B1

she said eagerly] MS; , A1, B1

"No Caonabo-Caonabo-no-no-no."] MS;

"No Caonabo-no-no-no." A1, B1

spears and] MS; , A1, B1

highly tempered sword] MS; highly-tempered A1, B1

unlooked-for execution] A1, B1; unlooked for MS

war; and] A1, B1; , MS

occurrence $_{\text {] }}$ MS; $\sim, \mathrm{A} 1, \mathrm{~B} 1$

Of course $]$ MS; , A1, B1

this warlike cacique] MS, A1; Cacique B1

After a few minutes ] MS; , A1, B1

followers,] MS; A1, B1

and laying] $\mathrm{MS} ; \sim, \sim \mathrm{A} 1, \mathrm{~B} 1$

speak, and] A1, B1; MS

earnestly, and] A1, B1; MS

saying in Spanish-] MS; , , A1, B1

$\mathrm{no}^{3}$ !- ] A1, B1; no- MS

darker,] MS, A1; . B1

his $^{2}$ ] MS; omit A1

Ozema;] A1, B1; , MS

forward singly, $\mathrm{MS} ; \sim, \sim \mathrm{A} 1, \mathrm{~B} 1$

encounters, but] MS; ; A1, B1

sun, and the head] A1, B1; sun, omit the head MS

stopped ] MS; , A1, B1

missive. A second] $\mathrm{K}$; missives. A $\sim \mathrm{A} 1$; missive, $\mathrm{a} \sim \mathrm{MS}$

which to their uninstructed minds appeared] $\mathrm{MS} ; \sim, \sim \sim \sim \sim, \sim \mathrm{A} 1, \mathrm{~B} 1$

In two minutes, neither Caonabo, nor] $\mathrm{A} 1, \mathrm{~B} 1 ; \sim \sim \sim$ niether $\sim, \sim \mathrm{MS}$

direction,] MS; A1, B1

Ozema,] MS; A1, B1 
$16.41 \quad$ plundered,] MS; ; A1, B1

*17.1 Ozema!"—] K; !—" MS; !" A1, B1

17.5 blew] MS, A1, B1; blow F1

$17.6 \quad$ and an hour] $\mathrm{MS} ; \sim, \sim \sim \mathrm{A} 1, \mathrm{~B} 1$

$17.7 \quad$ point, that] $\mathrm{MS} ; \sim \sim \mathrm{A} 1, \mathrm{~B} 1$

17.7 bay;] A1, B1; , MS

17.7 admiral's] MS, A1; Admiral's B1

17.8 injunction, to conceal his excursion, lest] A1, B1; $\sim \sim \sim \sim \sim$ MS

Alterations from the Manuscript to the First American Edition

This list contains all alterations that I have judged to be the result of Cooper's revisions in the first proof stage; they have thus been adopted into the text of the present edition. I have chosen to set them apart because they are a large category, and, in an editorial sense, are very straightforward. See the Historical Collation for variants between printed editions, as well as other variants between MS and printed editions that are less evidently authorial.

1.3 of late years,] A1; of late years - and well written, too,- MS

1.5 in this work] A1; of $\sim$ MS

1.6 view] A1; desire MS

1.8 In answer to this anticipated objection, we will state] A1; All that we have

1.11-12 to be] A1; omit MS

1.12 the portions of our subject that are likely to be disputed] A1; this part of the subject MS

1.35 superficial] A1; very accurate MS

1.42-43 Should the publicity which is now given to the consequences of commencing a day in the middle, have] A1;

If the publicity $\sim \sim \sim \sim \sim \sim \sim \sim \sim \sim$ should have MS

1.44

its ends, omit] A1; , we are quite indifferent which, MS

2.2 agreeable. omit] A1; agreeable. It will, quite likely, remove the objections of one portion of the community to this innovation, to be told that the English have already made this change. MS

2.5 much] A1; omit MS

2.6-7 he can be possibly by] A1; be omit by MS; possibly be by B1, F1

2.7 subordinate] A1; little MS

2.8 incidents omit connected] A1; incidents that are connected MS

2.8 more familiar] A1; known MS

2.8 it is hoped that they] A1; it is hoped that they MS

2.9 omit future] A1; all future MS

4.14 could] A1, B1; would MS

4.17 saw her omit] A1; in her MS

$5.14 \quad$ separated, omit $]$ A1; , while MS 
5.17

5.21

5.25

5.27

5.28-29

5.36

6.4

6.5

6.12

6.22-23

6.27

6.29-30

6.36

6.44

7.4

7.5

7.11

7.11

7.21

7.36

7.37

7.37

7.42

8.11

8.14-15

8.41

$* 8.42$

9.1

9.2

9.2

9.7

9.12

9.19

9.28

9.30

9.30

9.32

10.38

11.3-4

11.26

$11.39-40$

11.43

12.9 and that of two] A1; and two or three MS

about] A1; over MS

along] A1; through MS

through A1] into MS

by a foot-path which] A1; along that MS

again] A1; omit $\mathrm{MS}$

again] A1; omit MS

to follow omit] A1; to follow him MS

could] A1; would MS

wonder. \{paragraph break\} But it may] A1, B1; . But it may MS

the $^{1}$ ] A1; omit MS

the inhabitants] A1; those MS

a son] A1; the MS

this exemption] A1; the $\sim \mathrm{MS}$

perfect exemption] A1; omit exemption MS

fancy] A1; have fancied MS

usage] A1; opinion MS

or to comfort] A1; or omit comfort MS

many imagine] A1; omit $\mathrm{MS}$

no person] A1; no one MS

note] A1; see MS

on omit meeting] A1; on first meeting MS

than that which] A1; than omit which MS

also] A1; omit MS

Luis had not come on his little expedition unprovided with presents.] A1;

Luis had not come unprovided with presents, on his little expedition. MS

grateful pleasure] A1; gratitude MS

exhibit. \{paragraph break\} While] A1, B1; exhibit. While MS

person] A1; finery MS

advancing] A1; advanced MS

extended] A1; extending MS

Don Luis] A1; our hero MS

Our hero] A1; Luis MS

his person;] A1; him, MS

the count] A1; our hero MS; the Count B1

beautiful] A1; omit MS

understand] A1; comprehend MS

ere the day had] A1; was MS

cavalier] A1; fellow MS

in a certain degree] A1; to $\sim \sim \mathrm{MS}$

in thy sack] A1; omit MS

is in old Spain] A1; is truly in Spain MS

in that island,] A1, B1; omit MS

after running great risks] A1; by $\sim \sim \mathrm{MS}$ 
12.35 after all,] A1; omit MS

13.2 he longed] A1; longing MS

13.9 its mistress] A1; her MS

13.10 each of whom was] A1; and every tongue was eagerly uttering MS uttering MS

13.11 collected of them all] A1; collected MS

13.12-13 those around her] A1; all MS

13.17 to be] A1; was MS

13.20 heart of stone] A1; rock MS

13.21 necessary] A1; needed MS

13.21 omit $\mathrm{A} 1, \mathrm{~B} 1$; all MS

13.22

13.23

14.2

14.12

14.21

$14.21-22$

14.26

14.31

14.41

15.3

15.3

15.6

15.21

15.26

15.44

16.23

buckler omit on his arm] A1; bucker was on his arm MS

on her arm] A1; in her arms MS

which] A1; that MS

would] A1; could MS

omit without] A1; entirely without MS

would omit have thought] A1; would now have thought MS

undue] A1; much MS

a belief that she he sought] A1; the $\sim \sim$ her $\sim$ MS

those] A1; there MS, B1

threw] A1; placed MS

placed] A1; folded MS

governed] A1; who were governed MS

among] A1; between MS

raised] A1; uplifted MS

omit his followers] A1; all his followers MS

bright sun omit] A1; bright sun of the tropics MS

16.27 actually leaving] A1; omit leaving MS

16.30 however,] A1; omit MS

16.31 bull, omit] A1; bull, however, MS

16.42-43 by the Spaniards, Luis pointing it out to his companion.] A1; by both the Spaniards. MS

17.3 the fugitives] A1; the three MS

17.5 they] A1; the fugitives MS 


\section{$\underline{\text { Spelling Variants }}$}

I have used the same collation format as in the Historical Collation, with the exception of putting the line numbers to the right of the words themselves. These are organized alphabetically, for the ease of looking them up should readers wish to while reading. As in the Historical Collation, entries with an asterisk (*) have an accompanying textual note. The degree $\left(^{\circ}\right)$ indicates spellings that have been rejected to avoid confusion or ambiguity.

American and British Forms (all MS readings adopted in this edition)

ardor] MS; ardour A1, B1

connection] MS, B1; connexion A1

endeavor] MS; endeavour A1, B1

endeavoring] MS; endeavouring A1, B1

favor] MS; favour A1, B1

favorable] MS; favourable A1, B1

favored] MS; favoured A1, B1

favorite] MS; favourite A1, B1

honor] MS; honour A1, B1

honorable] MS; honourable A1, B1

laboring] MS; labouring A1, B1

meager] MS; meagre A1, B1
13.18

$14.3,5,15.37$

$8.37 ; 15.7$

$13.26 ; 15.10$

$14.7 ; 16.15 ; 17.8$

14.4

5.10

$4.37 ; 5.13 ; 9.17 ; 11.18 ; 13.3$

4.4

14.3

10.12

1.25

Antiquated Forms (all MS readings adopted in this edition)

ancles] MS; ankles A1, B1

bawble] MS; bauble A1, B1

dependance] MS; dependence A1, B1

despatched] MS; dispatched A1, B1

enured] MS, A1; inured B1

garlick] MS; garlic A1, B1

lowd] MS; loud A1, B1

publickly] MS; publicly A1, B1

vallies] MS; valleys A1, B1

shrunk] MS, A1; shrank B1

sprung] MS, A1; sprang B1

strided] MS; strode A1, B1

Venitians] MS; Venetians A1, B1

visitors] MS; visiters A1, B1

withall] MS; withal A1, B1
7.20

$9.5,11.37$

15.16

$5.19 ; 6.1$

16.24

3.39

16.32

4.1

4.41

6.19

7.42

16.16

11.42

5.8

10.40 


\section{Compound Words}

all engrossing] MS; all-engrossing A1, B1

any thing] MS, A1; anything B1

oblackguards] A1, B1; black guards MS

country-men] MS; countrymen A1, B1

every thing] MS, A1; everything B1

fellow creatures] MS; fellow-creatures A1

foot soldiers] MS; foot-soldiers A1, B1

free-thinkers] MS; free-|thinkers A1; Freethinkers B1

green sward] MS; greensward A1, B1

*ohawk's-bells] A1, B1; hawks'/hawk's MS

high born] MS; high-born A1, B1

hill side] MS; hill-side A1, B1

mid winter] MS; mid-winter A1, B1

new comer] MS; new-comer A1, B1

out-pourings] MS; outpourings A1, B1

play thing] MS; plaything A1, B1

sea weed] MS; sea-weed A1, B1; sea-|weed F1

war clubs] MS; war-clubs A1, B1
10.10

$1.15,9.18,12.5 ; 14.23$

12.34

9.34

12.1

1.38-39

13.5-6

9.42

14.13

$11.15^{*}, 29,32,34,38 ; 12.6$,

$18,20,35$

$4.17,6.12$

5.31

5.2

15.14

8.5

12.32

6.8

15.22

Misspellings (all A1 readings adopted in this edition)

$\begin{array}{ll}\text { oaccessories] A1, B1; accessaries MS } & 4.18 \\ \text { *anteroom] B1; ante-[room A1; anti-room MS } & 6.7 \\ \text { beleaguered] A1, B1; beleagured MS } & 14.30 \\ \text { cincture] A1, B1, F1; sincture MS } & 7.25 \\ \text { conceiving] A1, B1; concieving MS } & 3.26 \\ \text { ocurrent] A1, B1, F1; currant MS } & 7.26 \\ \text { palatable] A1, B1; patable MS } & 5.3 \\ \text { peculiarly] A1, B1; peculiarily MS } & 9.26 \\ \text { promontories] A1, B1; promentories MS } & 3.24 \\ \text { receiving] A1, B1; recieving MS } & 14.38 \\ \text { resemblance] A1, B1, F1; resemblence MS } & 7.30,44 \\ \text { 'several] A1, B1; severel MS } & 1.8 ; 3.29 ; 7.23 ; 8.11 \\ \text { shield] A1, B1; shild MS } & 14.37 \\ \text { their] A1, B1; thier MS } & 1.39 ; 4.35 ; 5.8,39 ; 8.14,22 ; \\ & 9.42,43,44 ; 12.19 ; 13.14 ; \\ & 16.34 ; 17.4 \\ \text { treachery] A1, B1; treachory MS } & 12.34\end{array}$




\section{End-of-line Hyphenation}

This is a list of the forms adopted in the current edition where a compound word is hyphenated at the end of the line in one of the printed editions. As hyphenated words form a considerable category of variants already, most of which are included under "Spelling Variants: Compound Words," this list duplicates some information. A plus sign (+) indicates the cross-listed entries. I have included line-end hyphenation from all the printed editions of 1840-41: these include A1, B1, and F1. I also include the MS forms, which - although the MS typically hyphenates without regard to line breaks-I have most often accepted as the reading for the present edition.

3.28

5.29

5.32

5.41

6.7

7.28

$+8.5$

8.32

$+9.34$

$+9.42$

10.38

$+11.39$

12.4

13.36

$+14.23$

$+14.20$ seaman] MS, A1, F1; sea-|man B1

foot-path] MS, B1; foot-|path A1; footpath F1

overlooked] MS, A1, F1; over-|looked B1

friendship] MS, A1, B1; friend-|ship F1

anteroom] B1; ante-|room A1, F1; anti-room MS

womanhood A1, F1; woman-|hood B1

out-pourings] MS; outpourings A1, F1; out-|pourings B1

child-like] MS, B1, F1; child-|like A1

country-men] countrymen A1, F1; country-|men B1

free-thinkers] MS; free-|thinkers A1; Freethinkers B1, F1

true-hearted] MS, A1, F1; true-|hearted B1

Ship Yard] MS; ship-|yard A1; ship-yard B1, F1

nobleman's] MS, A1, F1; noble-|man's B1

together] MS, A1, F1; to-|gether B1

any thing] MS; anything A1, F1; any-|thing B1

war clubs] MS; war-|clubs A1; war-clubs B1, F1 